\title{
Cross-Matching VIIRS Boat Detections with Vessel Monitoring System Tracks in Indonesia
}

\author{
Feng-Chi Hsu ${ }^{1,2} \oplus$, Christopher D. Elvidge ${ }^{2, *}$, Kimberly Baugh ${ }^{1,2}$, Mikhail Zhizhin ${ }^{1,2}$, \\ Tilottama Ghosh ${ }^{1,2}$, David Kroodsma ${ }^{3}{ }^{\mathbb{D}}$, Adi Susanto ${ }^{4,5}$, Wiryawan Budy ${ }^{6}$, \\ Mochammad Riyanto ${ }^{6}$, Ridwan Nurzeha ${ }^{7}$ and Yeppi Sudarja ${ }^{7}$ \\ 1 Cooperative Institute for Research in the Environmental Sciences, University of Colorado, Boulder, \\ CO 80303, USA; fengchihsu@mines.edu (F.-C.H.); kbaugh@mines.edu (K.B.); mzhizhin@mines.edu (M.Z.); \\ tghosh@mines.edu (T.G.) \\ 2 Earth Observation Group, Payne Institute, Colorado School of Mines, 1500 Illinois St., Golden, \\ CO 80401, USA \\ 3 Global Fishing Watch, Washington, DC 20036, USA; david@globalfishingwatch.org \\ 4 Department of Fisheries, Faculty of Agriculture, University of Sultan Ageng Tirtayasa, Banten 42124, \\ Indonesia; adisusanto@untirta.ac.id \\ 5 Indonesia-Center of Excellence for Food Security, University of Sultan Ageng Tirtayasa, Jalan Raya Jakarta \\ Km 4, Panancangan, Cipocok Jaya, Kota Serang, Banten 42124, Indonesia \\ 6 Department of Fisheries Resources Utilization, Faculty of Fisheries and Marine Sciences, Bogor Agricultural \\ University, Jl. Raya Dramaga Kampus IPB Dramaga Bogor, West Java 16680, Indonesia; \\ bud@psp-ipb.org (W.B.); mochammadri@apps.ipb.ac.id (M.R.) \\ 7 Kementerian Kelautan dan Perikanan, KKP Gedung Mina Bahari I Lt 5 Jl. Medan Merdeka Timur No. 16, \\ Jakarta 10110, Indonesia; ridwan.nurzeha@gmail.com (R.N.); abiyeppi62@gmail.com (Y.S.) \\ * Correspondence: celvidge@mines.edu
}

Received: 3 March 2019; Accepted: 19 April 2019; Published: 26 April 2019

check for updates

\begin{abstract}
A methodology had been proposed for cross-matching visible infrared imaging radiometer suite (VIIRS) boat detections (VBD) with vessel monitoring system (VMS) tracks. The process involves predicting the probable location of VMS vessels at the time of each VIIRS data collection with an orbital model. Thirty-two months of Indonesian VMS data was segmented into fishing and transit activity types and then cross-matched with the VBD record. If a VBD record is found within $700 \mathrm{~m}$ and $5 \mathrm{~s}$ of the predicted location, it is marked as a match. The cross-matching indicates that $96 \%$ of the matches occur while the vessel is fishing. Small pelagic purse seiners account for $27 \%$ of the matches. Other gear types with high match rates include hand line tuna, squid dip net, squid jigging, and large pelagic purse seiners. Low match rates were found for gillnet, trawlers, and long line tuna. There is an indication that VMS vessels using submersible lights can be identified based on consistently low average radiances and match rates under 45\%. Overall, VBD numbers exceed VMS vessel numbers in Indonesia by a nine to one ratio, indicating that VIIRS detects large numbers of fishing boats under the 30 Gross Tonnage (GT) level set for the VMS requirement. The cross-matching could be used to identify "dark" vessels that lack automatic identification system (AIS) or VMS.
\end{abstract}

Keywords: VIIRS; DNB; nighttime lights; VMS; IUU; boat detection; low light imaging; Indonesia

\section{Introduction}

The continuing decline in global fish stocks places an increasing importance on fishing vessel surveillance to better understand individual fishing grounds and to provide a basis for enforcement of fishing regulations and counter illegal, unreported, and unregulated (IUU) fishing activities. However, there is no uniform and mandatory reporting on fishing boat activity or their catch. Log books 
recording date ranges, locations, and catch weights are required in certain jurisdictions. However, these records are typically not submitted until after the vessel returns to its landing site and there is no centralized system for sharing these records. Individual fishing boats can be tracked in near real time using vessel tracks from automatic identification system (AIS) and vessel monitoring systems (VMS). However, these systems provide an incomplete view of fishing boat activity and the data are generally restricted in terms of access. In terms of completeness, the requirements for AIS and VMS generally cover only the larger boats, with smaller boats able to operate "under the radar." Indonesia has implemented a monitoring system for fishing vessels on a voluntary basis since 2003. While formal implementation of VMS attached on board of fishing vessel and fish carrier vessel for 30 gross tonnage (GT) or larger has been formalized by the Ministry Regulation number 42 in 2015, which represent approximately $10 \%$ of the domestic fishing fleet [1]. In the USA, VMS is required on fishing boats longer than 19 meters and, in certain federal waters, all fishing boats are required to carry VMS [2]. In other countries, such as the Philippines, there is no VMS requirement as of 2018. The International Maritime Organization (IMO) requires that all boats 300 GT and larger carry AIS [3]. The vast majority of fishing boats fall under these weight limits and are under no requirement to broadcast their location. A second shortcoming of VMS and AIS for vessel surveillance is that operators are able to evade detection by disabling their devices, reporting a false identification, or reporting a series of false locations. Amongst maritime enforcement agencies, there is substantial interest in identifying "dark vessels" that lack an accurate AIS or VMS signal. This is a tip-off of possible illegal fishing in certain fishing grounds. The only way to identify "dark vessels" is to combine AIS and VMS with complimentary vessels detection sources.

Certain satellite remote sensing systems can detect vessels and have potential value in fishery surveillance. High spatial resolution optical sensors are able to detect and characterize vessels under low cloud daytime conditions. Satellite synthetic aperture radar (SAR) systems are also able to detect offshore vessels and have the advantage of all-weather operations [4,5]. Also, high resolution optical imagery have been used to detect marine vessel activities [6-9]. The downside for these sources are that it may take several days to access the data, there are generally fees associated with the data access and global coverage is not currently available on a daily basis.

Data from meteorological satellite sensors have the favorable characteristics of providing global coverage, with data open access and near real time availability. In addition, there are long term archives for meteorological satellite data, which can be used to develop extended temporal records. The major disadvantage of meteorological satellite data for vessel detection is the spatial resolution, which is typically far too coarse for the detection of vessels using normal spectral bands. The exception to this is the detection of electric lighting on boats at night.

It has been known since the 1970s that lights from fishing boats can be detected with low light imaging data collected at night by sensors flown on weather satellites [10]. The low light imaging on these sensors is designed for the detection of moonlit clouds in the visible, but also enables the detection of electric lights present at the Earth's surface [11]. One of the lighting sources detected are fishing boats that deploy lights to attract catch. More recently, boat detection has been demonstrated using low light imaging data collected by the NASA/NOAA visible infrared imaging radiometer suite (VIIRS). Multiple groups have utilized VIIRS boat detection data in their research [12-16]. The first VIIRS was launched in 2011 and the second in 2017 [17], which will help to provide more coverage per day. In fact, the Earth Observation Group operates a near real-time VIIRS boat detection system which produces a nightly global mapping of VIIRS boat detections (VBD), and are available for open access download [18].

The purpose of this paper is to define a VBD cross-matching algorithm suitable for vessel track records like AIS or VMS, and to use this to characterize the VBD product. Studies had been carried out to match vessel track record with satellite based boat detection [19-23]. Most of these studies use vessel track records to verify the vessel detection result from selected scenes of satellite imagery. To aid satellite based vessel detection like VBD, whose records lack specific information on the boat detected, 
track data like VMS and AIS have to be further analyzed to provide information beyond vessel name and type. It is particularly important for fishery management to be able to answer questions like: is a detection an indication of fishing activity? Is it possible to identify "dark vessels" detected by satellite but lacking track records? What percentage of fishing vessels are detected by satellite?

To investigate these questions, we conducted a cross comparison analysis of VBD and VMS records for more than 3600 vessels spanning 32 months for Indonesia. The VMS records include unique identifiers for individual vessels and gear type registrations. By cross matching the VMS tracks with VBD it is possible to calculate the match rates and average VIIRS radiance for individual vessels. These results are aggregated for all the vessels having a specific gear type registration to answer the question on the types of fishing vessels detected by VIIRS.

In addition to cross matching, we also analyze VMS tracks for the status of the vessel at the time of recording. The VMS tracks are classified into four activity types by their location, speed and heading changes: landing, transit, stationary, and maneuvering. Such efforts help to answer the question on whether a VBD can be interpreted as "fishing." Separate match rate summaries are calculated for fishing and transit activity types.

Clearly, any new data source on vessel detection needs to be thoroughly examined and compared to other available data sources. Otherwise the users will not know how to interpret the data or develop standard operating procedures for their use. Our intention is to provide results on VBD in reference to a widely recognized vessel track data source.

\section{Methodology}

\subsection{Data Collection}

\subsubsection{VMS}

Under a cooperative research agreement with the Global Fishing Watch (GFW), we obtained 32 months of VMS data collected by the Indonesian Ministry of Marine Affairs and Fisheries (MMAF a.k.a. KKP). This consists of records for Indonesian fishing vessels larger than 30 GT from January 2014 to August 2016. The VMS records comprise 15 gear types with more than 3600 distinct vessels. The typical gap between vessel track records is about an hour. Here the term "track record" refers to the location report of the vessel at the time of reporting. The summary of gear types included in the database is shown in Table 1. The records include transmitter number, timestamp in UTC, latitude/longitude, registered gear type, vessel size and other useful information. There are nearly 29 million VMS records, with roughly 20 million track-hours. For easier reference to the gear types, abbreviations are devised as shown in Table 1 and used throughout this work.

Table 1. Summary of gear types in the vessel monitoring system (VMS) database.

\begin{tabular}{|c|c|c|c|c|c|}
\hline \multicolumn{2}{|c|}{ Gear Type } & \multirow{2}{*}{ Abbr. } & \multirow{2}{*}{ \# Vessels } & \multirow{2}{*}{$\begin{array}{c}\text { Average GRT } \\
\text { (Std. dev.) }\end{array}$} & \multirow{2}{*}{$\begin{array}{l}\text { Recorded Time } \\
\text { (Hours) }^{1}\end{array}$} \\
\hline Bahasa & English & & & & \\
\hline Pukat cincin pelagis kecil & Small pelagic purse seiner & PCK & 1085 & $99.9(50.0)$ & $3,357,444$ \\
\hline Bouke ami & Stick-held squid dipnet & BA & 502 & $71.2(28.2)$ & $1,441,394$ \\
\hline Rawai tuna & Longline tuna & RT & 428 & 113.5(84.7) & $1,806,814$ \\
\hline $\begin{array}{l}\text { Pukat cincin pelagis besar } \\
\text { degan satu kapal }\end{array}$ & $\begin{array}{l}\text { Large pelagic purse seine } \\
\text { with one ship }\end{array}$ & РСОВ & 417 & $129.9(55.9)$ & $1,936,373$ \\
\hline Pengangkut & Carrier $^{3}$ & $\mathbf{P}$ & 386 & $300.8(539.0)$ & $1,825,319$ \\
\hline Pukat ikan & Trawler & PI & 205 & $210.9(128.3)$ & 6777 \\
\hline Pancing cumi & Squid jigging & PC & 195 & $107.8(41.3)$ & $1,377,622$ \\
\hline Jaring insang oseanik & Oceanic gill net & $\mathrm{JIO}$ & 172 & $142.6(106.1)$ & 742,990 \\
\hline Jaring liong bun & Shark gillnet & JLB & 139 & 48.7(13.5) & 82,034 \\
\hline Rawai dasar & Basic longline & $\mathrm{RD}$ & 132 & $77.9(59.4)$ & 945,630 \\
\hline Hand line tuna ${ }^{2}$ & Hand line tuna & HLT & 69 & $98.46(43.8)$ & 88,705 \\
\hline Huhate & Pole and line & $\mathrm{H}$ & 67 & $63.9(18.8)$ & 205,372 \\
\hline Pukat udang & Shrimp trawl & PUD & 42 & $152.8(34.1)$ & 0 \\
\hline
\end{tabular}


Table 1. Cont.

\begin{tabular}{lllccc}
\hline \multicolumn{2}{c}{ Gear Type } & Abbr. & \# Vessels & $\begin{array}{c}\text { Average GRT } \\
\text { (Std. dev.) }\end{array}$ & $\begin{array}{c}\text { Recorded Time } \\
\text { (Hours) }{ }^{\mathbf{1}}\end{array}$ \\
\cline { 1 - 2 } $\begin{array}{l}\text { Pukat cincin grup pelagis } \\
\text { kecil }\end{array}$ & $\begin{array}{l}\text { Small pelagic purse } \\
\text { seine group }\end{array}$ & PCGK & 12 & $83.8(18.9)$ & 0 \\
Pancing ulur & Hand line & PUR & 4 & $107.5(34.1)$ & 0 \\
\hline
\end{tabular}

${ }_{1}^{1}$ Record time: hours are calculated with record interval less than $2 \mathrm{~h}$, excluding erroneous records. ${ }^{2}$ Recorded in English in track database. ${ }^{3}$ Carriers are vessels which collect catches from fishing vessels. $\bullet$ Gear types with more than 1 million hours recorded in the database are in boldface. • Gear types Bubu (Fish trap) and Pukat cincin grup pelagis besar (Large pelagic purse seine group) were found in the vessel list, but do not have any record in the VMS track database.

\subsubsection{VBD}

The VBD data used in this study were downloaded from the EOG website [18] for the corresponding time range, i.e., from January 2014 to August 2016. The VBD records were filtered to a rectangular area covering the Indonesian Fishery Management Zones (Wilayah Pengelolaan Perikanan, WPP) as shown in Figure 1. The VBD data used in this study were produced by the V23 algorithm. VBD records were also imported to the same database as the VMS records for further processing. The VBD data were provided in the form of CSV files, with data from columns listed in Table 2 used in the study.

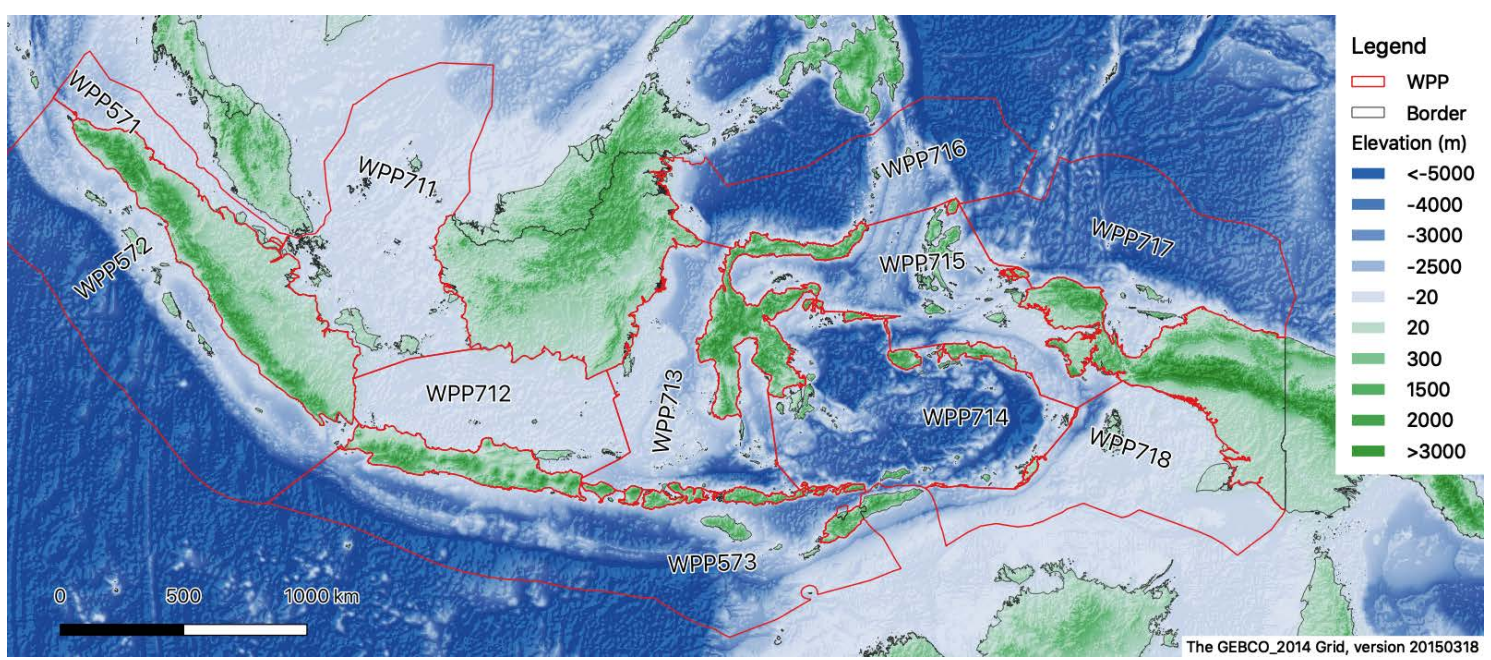

Figure 1. Bathymetry map of Indonesian waters with Indonesia Wilayah Pengelolaan Perikanan (WPP). WPP regions courtesy to Ministry of Marine Affairs and Fisheries (KKP) [24].

VBD from 2014-2016 being a dataset derived from observations of a single polar orbit satellite with nominal swath of $3000 \mathrm{~km}$, can cover the globe daily, with minimal coverage of 1 at the equator, and increased coverage closer to both poles. Indonesia usually gets 1 coverage, and 2 coverages in the orbit overlap area. The band used for detection in VBD is VIIRS day night band (DNB), with a nominal pixel footprint of $742 \mathrm{~m}$ by $742 \mathrm{~m}$. VBD also adopts data from VIIRS Nightfire which was also a product of EOG [25], to prevent gas flares of oil platforms from being recognized as lit vessels [16]. 
Table 2. Attributes provided by visible infrared imaging radiometer suite boat detections (VBD) used in this study.

\begin{tabular}{lll}
\hline Name & Explanation & Unit \\
\hline ID_Key & Unique key for each VBD record & Unitless \\
Lat_DNB & Latitude of the center of DNB pixel & Degrees \\
Lon_DNB & Longitude of the center of DNB pixel & Degrees \\
Date_Mscan & Timestamp in UTC at the middle of the scan line & Unitless \\
Rad_DNB & Radiance of the DNB pixel & $\mathrm{nW} / \mathrm{sr} / \mathrm{cm}^{2}$ \\
QF_Detect & Quality flag (type) of the VBD detection & Unitless \\
\hline \multicolumn{3}{c}{ Note: See VBD web site [18] for details on header definitions. }
\end{tabular}

\subsection{Vessel Location Prediction}

To match VMS to VBD, the vessel location at the time of satellite overpass has to be known. This is achieved by interpolating the vessel location between neighboring records at the time of anticipated satellite overpass time. The location interpolation is shown as

$$
\begin{aligned}
& X_{t}=X_{1}+\frac{X_{2}-X_{1}}{T_{2}-T_{1}} \times\left(T_{t}-T_{1}\right) \\
& Y_{t}=Y_{1}+\frac{Y_{2}-Y_{1}}{T_{2}-T_{1}} \times\left(T_{t}-T_{1}\right),
\end{aligned}
$$

where $X_{t}$ and $Y_{t}$ are coordinates of the vessel at the satellite overpass time $T_{t} . X_{1}$ and $Y_{1}$ are vessel coordinates in VMS records immediately prior to $T_{t}$. Likewise, $X_{2}$ and $Y_{2}$ are vessel coordinates in VMS records immediately after $T_{t}$. This can also be re-written to do extrapolation of vessel location at the beginning and ending of vessel tracks. Such process are called vessel location prediction in this study. The overall process is shown in Figure 2.

Before performing vessel location prediction, the VMS track record needed to be cleaned to remove records with erroneous timestamps or coordinates. Records that indicate moving speed larger than 30 knots were also neglected.

VMS track series were processed by UTC date. The record that was nearest to local midnight was selected, whose coordinate and timestamp were used as seed to begin the search for the nearest satellite overpass time, here referred as the predicted time.

A program, VIIRS overpass predictor, was developed to find the closest satellite overpass time for a given location and time. The orbital location of satellite at any given time can be propagated with SGP4 model [26] and proper two line element (TLE) [27]. TLE provides all the necessary parameters describing the satellite orbit at a specific time. TLE is retrieved from CelesTrak which usually being updated daily [28].

Since TLE was frequently updated, the program finds the TLE closest to the seeding time, and it propagates satellite location with 10 min interval until the seeding location passed the scanning plane and is visible, i.e., the shortest distance from target to satellite path is within the scanning swath. Then it reverses the direction of propagation with $1 / 10$ of the previous time step until the seeding location passed the scanning plane again. The time step is then reversed with $1 / 10$ of its current setting. The process is repeated until the change of angle between the satellite to the visible observer and the scanning plan is less than 0.0001 degrees for the current time step. The time step is then reset and the next loop is initiated with seed time advanced by $60 \mathrm{~min}$ from the current predict time to search for the next possible overpass. When the given coordinate is within the orbital overlap zones, it is possible to find multiple predict overpass times. The process is continued until the seed time is $24 \mathrm{~h}$ advanced from the first seed time. By verifying the predicted time with VBD records, the precision of the VIIRS overpass predictor is determined to be $\pm 2 \mathrm{~s}$. 


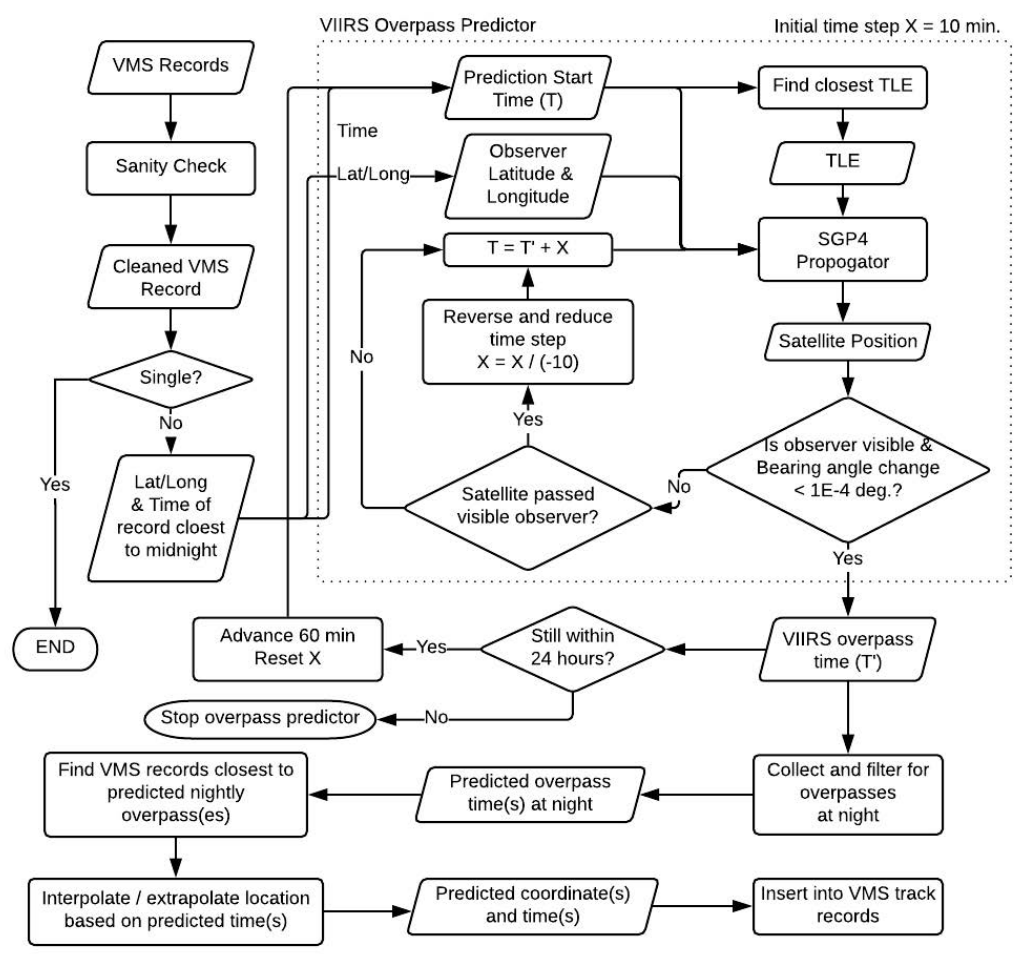

Figure 2. Flow chart of vessel location prediction at satellite overpass.

The predicted VIIRS overpass time is then used to interpolate the vessel location between immediate neighboring VMS track before and after it. If the predicted VIIRS overpass time is beyond the ending or starting record of the VMS track series, extrapolation is adopted. The process is skipped if the predicted VIIRS overpass time is $2 \mathrm{~h}$ away from any nearest VMS track records. The calculated record with predicted VIIRS overpass time and interpolated vessel location is referred as predicted record. Such records are inserted into the VMS database and treated as part of the VMS track series.

\subsection{VMS Record Status Classification}

VMS tracks with predicted records inserted are then classified by their type of activity. In this study we tried to separate the type of activity into maneuvering (M), transit (T), stationary (S), and landing (L). Briefly speaking, $\mathrm{M}$ records were those with lower speed and larger heading change, while $\mathrm{T}$ records were those with higher speed and smaller heading change. $S$ and $L$ records were those not moving for a period of time, with $\mathrm{L}$ records were found close to recognized landing sites. We specifically call vessels in $\mathrm{M}$ and $\mathrm{S}$ as being fishing $(\mathrm{F})$. There are a number of different methods developed to perform status classification of track records [29]. Here the method proposed by de Souza et al. [30] for long line vessels using an $\mathrm{R}$ package called adehabitatLT [31] was chosen.

Status classification as shown in Figure 3 was applied on one vessel within a calendar year at a time. If the number of track records within a calendar year was less than 50, the track will not be subjected to classification. The adehabitatLT package requires the track to be evenly separated temporally. The VMS records were not strictly $1 \mathrm{~h}$ apart, hence it had to be normalized to a regular hourly interval before classification.

The coordinates were reprojected to corresponding universal transverse mercator (UTM) zones in accordance to the average latitude and longitude of the selected annual track to have the calculation carried out in meters instead of degrees. Although vessels can cross multiple UTM zones, the errors caused were assumed negligible in the scope of this study. This was because fishing vessels usually take regular routes and are unlikely to cross more than two UTM zones. 
The process of applying adehabitatLT can be simplified in two stages. First, the annual track was cut into segments. The maximum likelihood method gives the most likely number of segments in the track, which describes how many times a vessel changed its pattern of maneuvering in the given track. Then for each segment, we found the most likely model from the predefined velocity model for each segment [31].

The velocity model in this study was defined as a series of Gaussian distribution with mean $=2$ $(\mathrm{km} / \mathrm{h}) \times n$ where $n=1$ to 10 , and standard deviation as $2.5(\mathrm{~km} / \mathrm{h})$. For our purpose, segments with velocity model lower than or equal to model 5 , i.e., velocity normal distribution of mean velocity of $10 \mathrm{~km} / \mathrm{h}$ with standard deviation of $2.5 \mathrm{~km} / \mathrm{h}$, are determined to be maneuvering (M). Fast moving segments were deemed in transit $(\mathrm{T})$. If slow moving segments have an average cosine of turning angle between records larger than 0.8 or smaller than -0.8 , i.e., angle smaller than approximately 36.8 degrees, then the segment was also considered as in transit.

Besides checking by segment, the track was also checked record-wise for stationary records. First, the track was scanned for stationary records. If any of the four consecutive records moved less than $100 \mathrm{~m}$, their status was set to stationary (S). If the whole track was stationary, no further process was applied, and the whole track was marked as stationary. The distance to the nearest coast of these stationary records are then determined by querying the NASA coastal distance database [32]. The status of records which are within $2 \mathrm{~km}$ from the nearest coast were overridden to landing (L), and a possible landing site was written the the record by referencing the list of known landing sites, which is extracted from the MMAF website [33].

Segment-wise and record-wise results were then consolidated and written into normalized track record, which was then de-normalized back to its original time stamp and written into the database. The same algorithm was applied to all gear types, as we found the output to be satisfactory within the scope of this study.

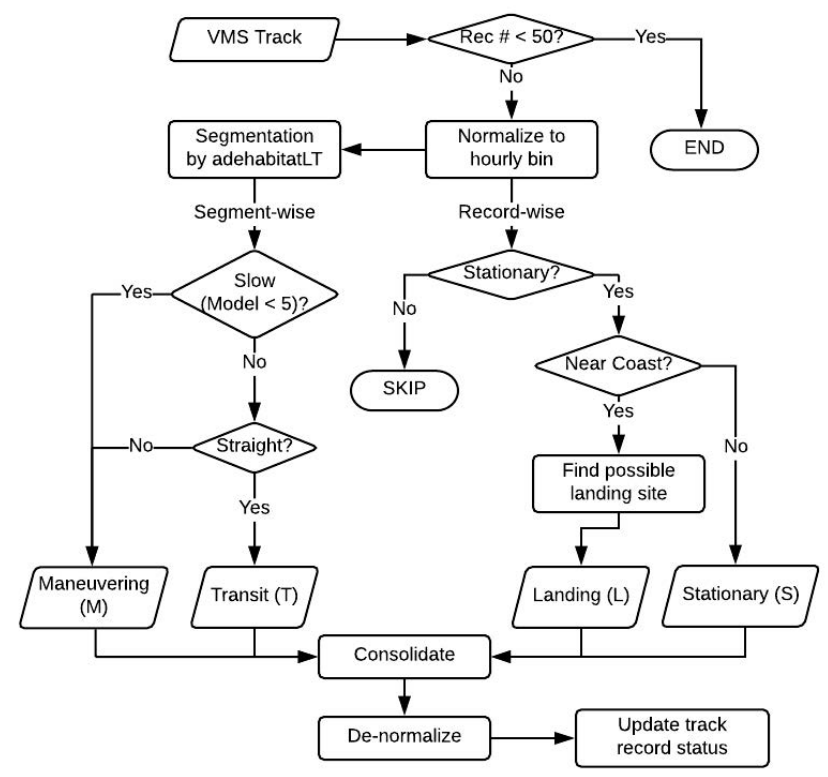

Figure 3. Flow chart of VMS track status classification.

\subsection{VBD Cross Matching}

The threshold of matching predicted VMS record to VBD was set to be within $700 \mathrm{~m}$ and $5 \mathrm{~s}$. The reason to set the distance threshold at $700 \mathrm{~m}$ was in consideration of the VIIRS-DNB pixel footprint size, while a temporal threshold of $5 \mathrm{~s}$ was because the precision of overpass prediction was \pm 2 s. Such a threshold was considered to provide enough tolerance. If a VBD match was found for 
any predicted record, the matched VBD record ID along with the distance and temporal difference was recorded.

There were cases when a VBD record was found with similar coordinate in neighboring orbits. Being able to add temporal discrimination in matching VMS and VBD gave us the ability to match the exact VBD record within orbit overlap areas.

\section{Results}

\subsection{Status Classification Result}

Examples of classification results are shown in Figure 4. Figure 4a shows the track of a small pelagic purse seiner vessel (PCK) from January to August 2016. It is clear that the vessel has a rather simple pattern with single landing site of Pekalongan and focused fishing ground in Makassar Strait. The red dots indicate VMS records that are recognized as in transit (T). Blue dots are those in fishing (F), i.e., maneuvering (M) or stationary (S). Green dots represents when the vessel was near the coast, and supposed to be landing at Pekalongan in this case. The vessel also appears to be stationary near Saburu Island. Figure $4 \mathrm{~b}$ shows the track of a squid jigging vessel (PC) also from January to August 2016. The vessel travelled for weeks from Jakarta to Arafura Sea for fishing in the two most popular squid jigging sites. It appears that the vessel got its supply from Merauke while operating continuously in the Arafura Sea for months. It also indicates that the vessel had stopped at Jampea Island. It would be reasonable to assume that it also landed its catch in Merauke as well. The vessel returned to Jakarta after its long voyage.

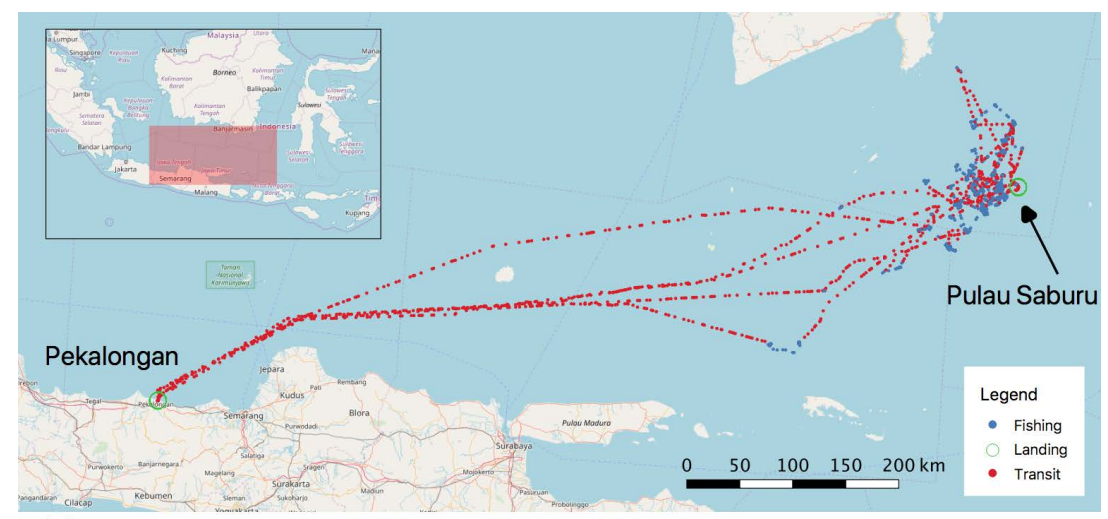

(a)

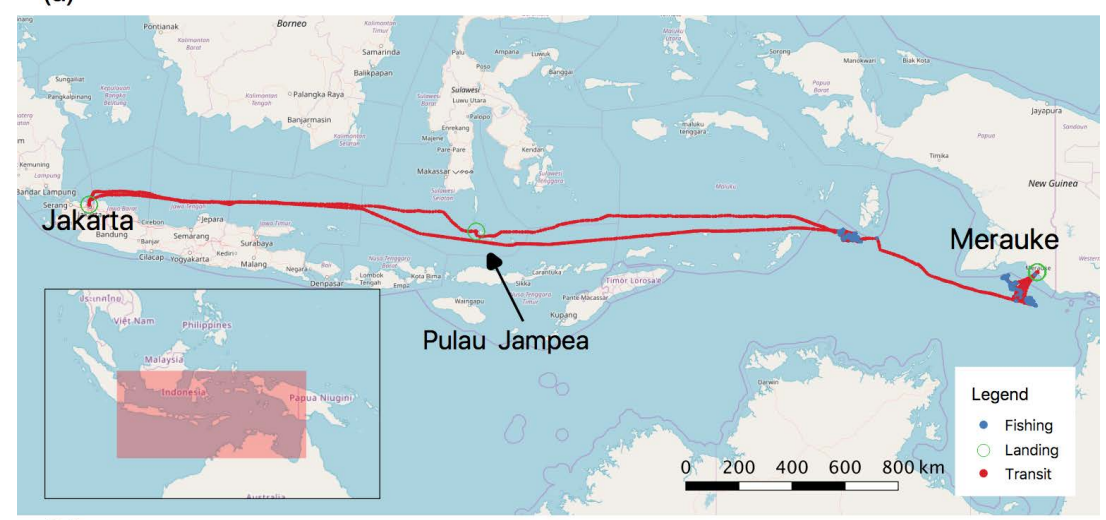

(b)

Figure 4. (a) Pelagic purse seiner vessel (PCK) track classification result of VMS track in 2016 from January to August. The vessel had been fishing in Makassar Strait, and landed in Pekalongan and Saburu Island. (b) Squid jigging vessel (PC) track classification result of VMS track in 2016 from January to August. The vessel had been fishing in the Arafuru Sea and the Banda Sea, and landing in Merauke, Jampea Island, and Jakarta. Base map provided by Open Street Map [34]. 
Figure 5 visualizes the distribution of velocity and heading changes for moving VMS records, i.e., transit and maneuvering. It is clear that vessels in transit travelled straight for most of the time, with velocity mostly found at $10 \mathrm{~km} / \mathrm{h}$. For those in maneuvering, they often changed heading with speed around 1 to $2 \mathrm{~km} / \mathrm{h}$ and wider spread of heading changes.

(a) Transit

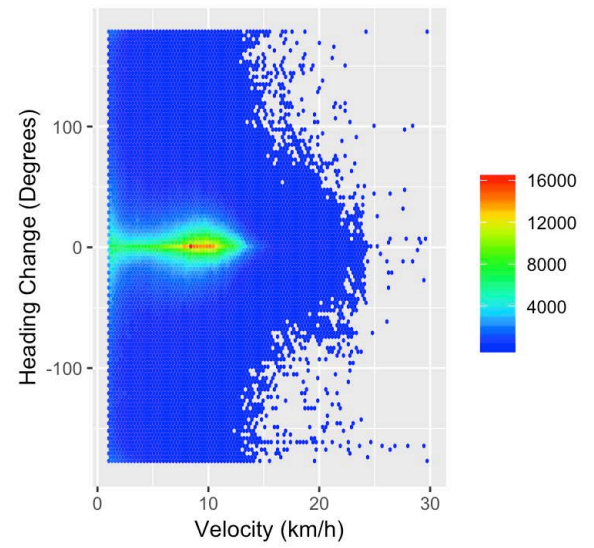

(b) Manuevering

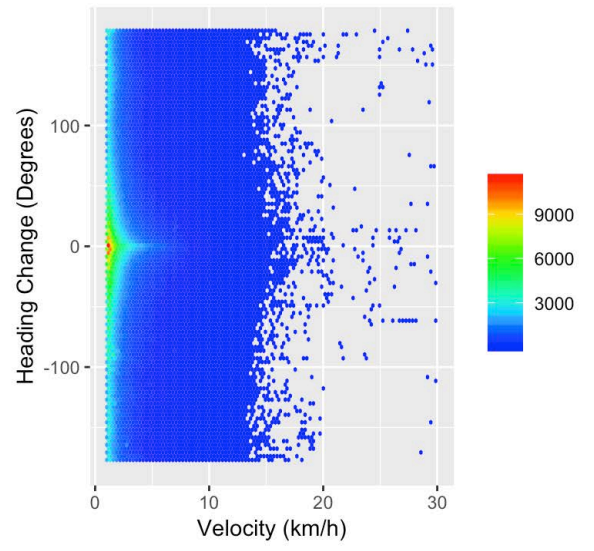

Figure 5. Velocity and heading change for all vessels in the VMS database. (a) For records in transit and (b) for records in maneuvering. Markers are colored by the number of VMS records.

\subsection{Cross-Matching Result}

Here the result of cross-matching is displayed. Figure 6 shows the density map in 0.1 degree cells, with VMS records marked as fishing (F) in pink and red, and cells with matched VBD record as green, for the top 6 gear types whose recorded time is larger than 1 million hours as shown in Table 1. Carrier $(\mathrm{P})$ is excluded despite having more than 1 million hours of recorded time for it is not a fishing vessel. The gear type with most recorded hours next to $\mathrm{P}$, Basic longline (RD), is included instead.

It is intriguing to see how each gear type prevails distinctive water. While stick-held squid dipnet (BA)/squid jigging (PC)/small pelagic purse seiner (PCK)/RD vessels focus mainly in the Java sea and the Arafura sea, large pelagic purse seine with one ship (PCOB) and longline tuna (RT) spreads widely into the Indian Ocean. The later two gear types were larger in gross tonnage as shown in Table 1, which implies they were better adapted to rough waters and can stay in the oceans longer without resupply.

Figure 6 shows the density map also in 0.1 degree cells of VMS records with matched VBD record found, with Figure $6 \mathrm{f}$ showing the VBD records with detection quality flag (QF_Detect) of 1, i.e., high quality boat detection, from 2014 to 2016 for reference. For those gear types which show small area as green indicates having fair chance of successful cross-match, i.e., finding VBD record match for the predicted VMS record. BA, PC, and PCOB all have similar distributions for VMS fishing records and their VBD matches. PCK only shows similar patter in WPP (Fishery Management Zone) 711, 712 and 713. RT although shows wide spread of VMS fishing records in south of Java, west of Sumatra, and the Arafura Sea as shown in Figure 6e, it is only occasionally matched, with most of them happening in the Arafura sea. RD operation was heavily found in the Arafura sea, and was rarely being matched by VBD records.

Figure 7 shows the gear type composition of VMS record with VBD found for each WPP region. PCK is dominant in WPP 571, 572, 711, 713, 715, 716, and seen in WPP 573, 712, 714, 717. PCK is seen in all 11 WPP regions with 10 having substantial to dominant proportions. PC has absolute weight in WPP 718, while WPP 718 also has the largest amount of VMS match records. BA matches mostly exist in WPP 711 and 712, and some in WPP 718. PCOB is most visible in WPP 573, while RT show substantial proportion in WPP 717 and 714 . However, most vessels were detected by VBD in WPP 572, $711,712,713,573$, and 718 . The rest of the WPPs barely have any matches. 

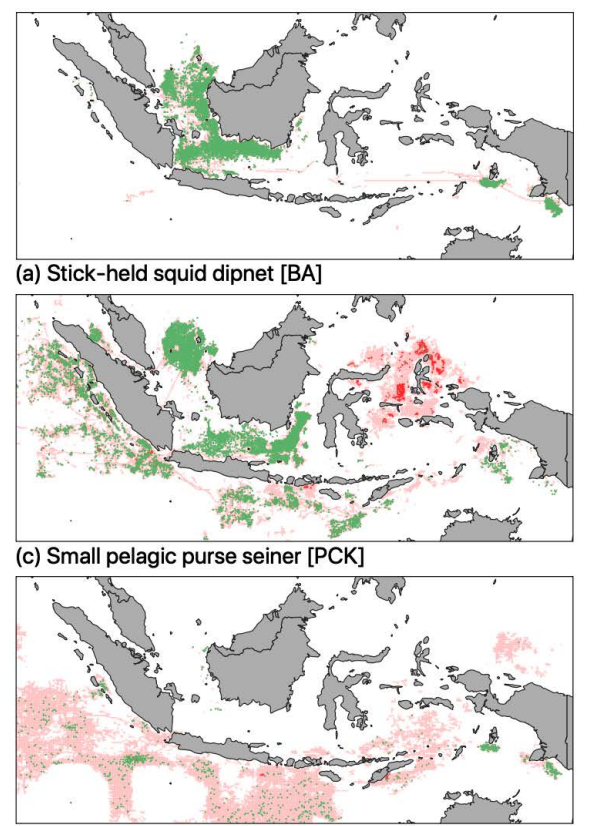

(e) Longline tuna [RT]
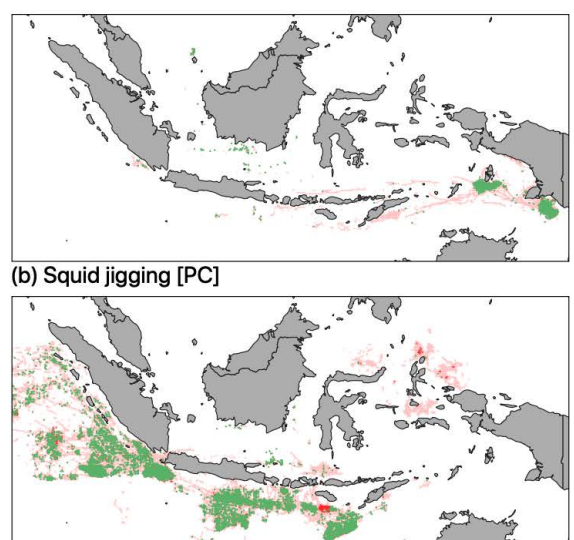

(d) Large pelagic purse seine with one ship [PCOB]

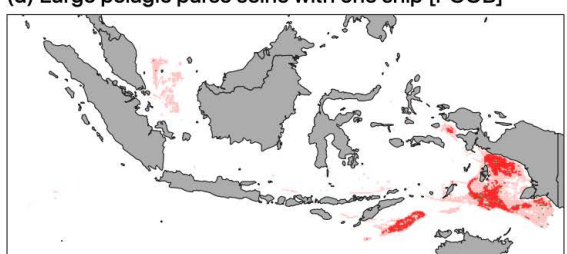

(f) Basic longline [RD]

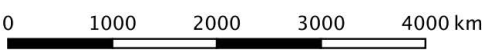

Figure 6. Spatial distribution of VMS fishing records (pink and red) with matched VBD detection (green) for major gear types in 0.1 degree cells.

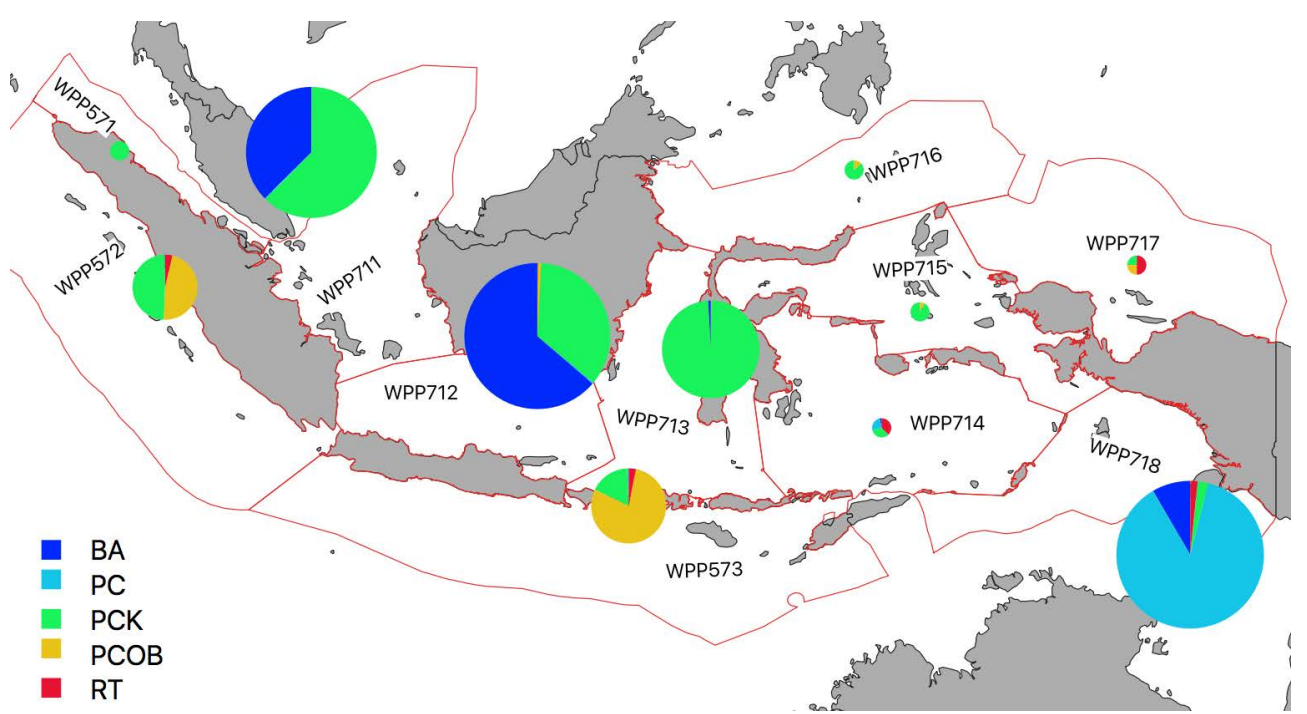

Figure 7. Composition of major gear types for matched VMS records in each WPP region. The size of the pie chart indicates the total number of matched VMS records for major gear types included, note the size is not strictly proportional to the actual number. WPP regions courtesy to KKP [24].

Since polar orbiting satellites like Suomi National Polar-orbiting Partnership (Suomi NPP) which carries VIIRS only observes a given location in limited time range, it is necessary to evaluate how much fishing activities are accounted for in VBD. As shown in Figure 8, VIIRS overpass window only covers 22:00 to 4:00 in local time for Indonesia, and is most frequent at 1:00.

Here we overlay the temporal distribution of records in fishing status for BA, PC and PCK, which were the most dominant gear types as shown in Figure 7, to show their diurnal patterns of fishing and stationary in Figure 8. It is clear that BA, PC and PCK tended to be in fishing status at 24:00 to 3:00 local time, with peak at 1:00. The fact that the time range when vessels of these gear types 
were at fishing status coincides with the VIIRS overpass window suggests that VIIRS observation can account for most fishing activities at night.

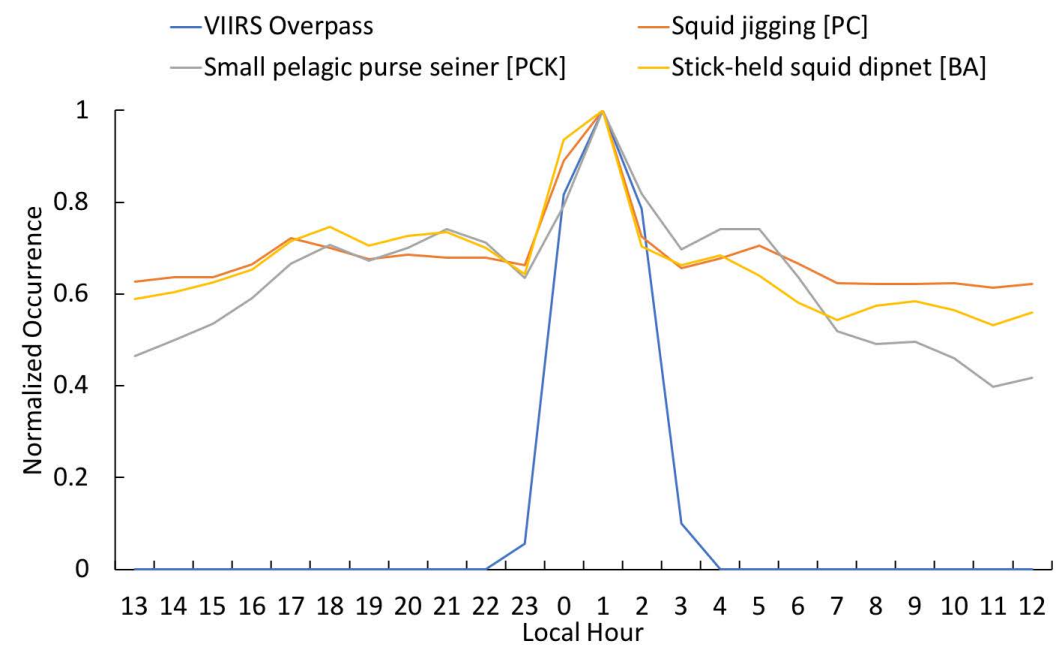

Figure 8. Distribution of normalized occurrence for visible infrared imaging radiometer suite (VIIRS) overpass over Indonesia, and PC and PCK in fishing status.

\subsection{Match Rate}

Once it was possible to match predicted VMS records, i.e., vessel location at the time of predicted VIIRS overpass, with VBD, it was natural that we would like to quantify the performance of cross-matching for each gear type. Table 3 displays details of match rate calculations for each gear type available in the VMS database. Small pelagic purse seiners (PCK) accounted for $27 \%$ of the matches.

The raw match rate for certain gear type $\left(R_{\text {raw }, i}\right)$ was the simplest way to evaluate the cross match performance for gear type $i$. It was calculated as

$$
R_{\text {raw }, i}=\frac{C_{m, i}}{C_{p, i}}
$$

where $C_{m, i}$ is the match count, and $C_{p, i}$ is the prediction count, for gear type $i$. Below we drop the $i$ sign to simplify the formulas. The prediction count is the sum of interpolated vessel location records within the time period covered by the dataset.

However, the number of predicted vessel locations should be adjusted for the scenario when heavy cloud cover blocks vessel detection. Rather than screen out all pixels having cloud using the VIIRS on/off cloud mask, we wanted to include a broader range of cloud conditions, as we know from visual inspection that VBD produces detections even in the presence of some cloud cover. To address this issue, we developed a cloud transparency index based on the VIIRS imaging band five. I5 observes longwave infrared radiation at 10.5 to $12.4 \mu \mathrm{m}$ [35]. Over the warm waters surrounding Indonesia, clouds are colder than the underlying ocean surface, and will have lower radiance values in the I5 imagery. To derive the cloud transparency index, we generated a histogram tallying the number of VBD detections for 600 narrow I5 radiance bins. Then, as the reference, we made a companion histogram tallying the number of ocean background I5 pixels for the same radiance bins. By dividing these two histograms, a clear linear relationship emerged, depicting cloud transparency as a function of I5 radiance. As the 5 radiance increased, the number of VBD detections increased, indicating increased cloud transparency. At an 15 radiance of 1.5 or less, the cloud was effectively opaque, blocking all vessel detections. 15 radiances in the range of 7 to 8 corresponded to the highest level of transparency, largely cloud-free conditions. We then converted the VBD/background ratio values to a cloud transparency index by rescaling from 0 to 1 (Figure 9). Thus, we were able to take the 15 radiance and calculate 
cloud transparency. We used this capability to adjust the number of predicted VMS locations prior to calculating match rates.

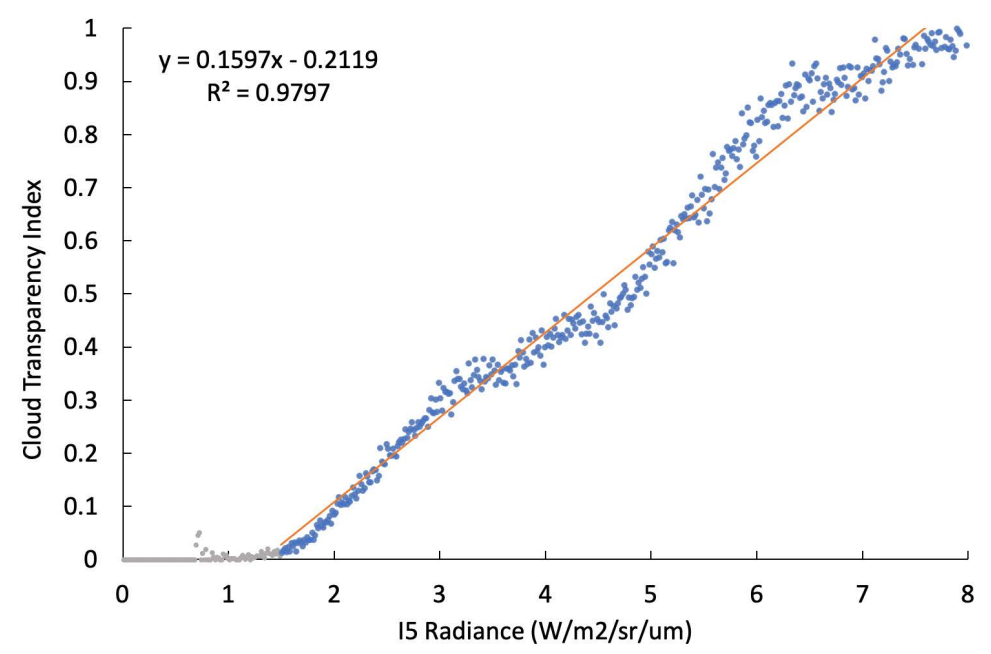

Figure 9. VIIRS I5 radiance and cloud transparency index. I5 values between 1.5 and 8 were included in the regression. 5 radiances higher than 8 will have a transparency index of 1 (clear sky), and lower than 1.5 will have a transparency index close to 0 (opaque sky).

We corrected for the effect of clouds on VBD using this atmospheric transparency as correction factor as

$$
C_{p_{-} a d j}=\sum_{r} \frac{C_{p}(r)}{O(r)}
$$

where $r$ is the $\mathrm{I} 5$ radiance of each bin, $O(r)$ is the cloud transparency index in regards to $\mathrm{I} 5$ radiance, and $C_{p_{-} a d j}$ is the adjusted prediction count. With the adjusted prediction count $\left(C_{p_{-} a d j}\right)$, the adjusted match rate can be calculated as

$$
R_{a d j}=\frac{C_{m}}{C_{p \_a d j}} .
$$

We were particularly interested to know the chance of a vessel to be detected by VBD in particular operation status. Such specialized match rate is defined as

$$
\begin{aligned}
& R_{a d j}(F)=\frac{C_{m}(F)}{C_{p_{-} a d j}(F)}, \\
& R_{a d j}(T)=\frac{C_{m}(T)}{C_{p_{-} a d j}(T)},
\end{aligned}
$$

where $F$ and $T$ denotes the status: "fishing" or "transit".

Given all the information, we can also calculate the probability of a VBD detection being in fishing status as

$$
P(F)=\frac{\sum_{i} C_{m, i}(F)}{\sum_{i} C_{m, i}(F)+\sum_{i} C_{m, i}(T)},
$$

where $i$ denotes each gear type. Note that we only account for matches in the status of fishing and transit in the denominator. That is because vessels in landing status were not considered to be in operation, and VBD could be influenced by city lights which causes false detection. In this study, $P(F)$ is determined to be $96.42 \%$. 
Table 3. Match rate for each gear type.

\begin{tabular}{lccccc}
\hline Gear Type & Matches $^{1}$ & Predictions $^{2}$ & Rate $_{\text {raw }}{ }^{3}$ & Rate $_{\text {adj }}(\boldsymbol{F})^{4}$ & Rate $_{\text {adj }}\left(\boldsymbol{T}^{5}{ }^{5}\right.$ \\
\hline Hand line (PUR) & 108 & 259 & $41.7 \%$ & $82.8 \%$ & $5.8 \%$ \\
Stick-held dipnet (BA) & 40,999 & 101,111 & $40.5 \%$ & $80.8 \%$ & $10.4 \%$ \\
Squid jiggiing (PC) & 35,001 & 77,431 & $45.2 \%$ & $78.3 \%$ & $9.1 \%$ \\
Hand Line Tuna (HLT) & 3691 & 10,961 & $33.7 \%$ & $72.7 \%$ & $5.8 \%$ \\
Small pelagic purse seiner (PCK) & 59,638 & 242,727 & $24.6 \%$ & $58.9 \%$ & $7.7 \%$ \\
Large pelagic purse seine with one ship (PCOB) & 18,225 & 121,535 & $15.0 \%$ & $32.9 \%$ & $8.3 \%$ \\
Pole and line (H) & 114 & 12,998 & $0.9 \%$ & $10.9 \%$ & $0.5 \%$ \\
Longline tuna (RT) & 3159 & 72,817 & $4.3 \%$ & $10.2 \%$ & $4.3 \%$ \\
Trawler (PI) & 1069 & 28,203 & $3.8 \%$ & $8.3 \%$ & $5.6 \%$ \\
Oceanic gill net (JIO) & 1259 & 49,073 & $2.6 \%$ & $6.3 \%$ & $2.5 \%$ \\
Shrimp trawl (PUD) & 247 & 11,643 & $2.1 \%$ & $6.6 \%$ & $2.5 \%$ \\
Carrier (P) & 293 & 63,541 & $0.5 \%$ & $6.2 \%$ & $0.9 \%$ \\
Shark gillnet (JLB) & 82 & 12,630 & $0.7 \%$ & $1.2 \%$ & $0.3 \%$ \\
Small pelagic purse seine group (PCGK) & 4 & 1047 & $0.4 \%$ & $0.4 \%$ & $2.2 \%$ \\
Basic longline (RD) & 104 & 50,447 & $0.2 \%$ & $0.3 \%$ & $0.2 \%$ \\
\hline
\end{tabular}

${ }^{1} C_{m}$ : Count of matched records. ${ }^{2} C_{p}$ : Count of predicted records. ${ }^{3} R_{\text {raw }}$ : Raw matching rate. ${ }^{4} R_{a d j}(F)$ : Adjusted matching rate for fishing status. ${ }^{5} R_{a d j}(T)$ : Adjusted matching rate for transit status. 


\subsection{Average Radiance and Match Rate}

Through VMS/VBD cross-matching it was possible to identify the gear types that are widely using lights to attract catch and those that are not. It is possible that vessels of the same gear type may differ in both wattage and the manner in which lights are deployed. There is evidence for regional differences in lighting for small pelagic purse seiner (PCK). As shown in Tables 4 and 5, PCK in different regions exhibit different average radiances and hence may have different raw match rate. The results in Table 4 shows that PCK in the Natuna Sea and the Makassar Strait has near $45 \%$ chance of being detected by VBD, while those in Malaku Sea have less than $1 \%$. Table 5 shows that PCK used brighter lights and were more detectable in WPP 711 near the Natuna Sea as well as WPP 712 and 713 near the Makassar Strait. PCK operating in the Maluku Sea in WPP 715, 716 and 717 did not seem to use light at all. We suspect such difference was caused by the extensive use of fish aggregating devices (FADs) in WPP 715, 716, and 717. By attracting catch with FADs, fishing vessels only need enough lighting for operating, eliminating the use of excessive lighting.

FADs are floating objects with extensions hanging in the water that collect sea-life, such as that attract pelagic species including tuna, mackerel, scads, sardines, etc. There are two common types of FADs. Pontoon or box type is made of steel, and raft type made of bamboo. Attractors hanging below the surface of water can be made of coconut leaves, nipah leaves, and pinag leaves [36]. These devices are anchored to prevent from drifting. Fishes will tend to be attracted by the hanging attractors or smaller species aggregated around the device, therefore fishermen do not require strong lights to attract catches or baits. FADs are known to be a old and common practice in Indonesia, enabling fishermen to use minimal effort for maximal catch [36].

Table 4. Match rate for pelagic purse seiner vessel (PCK) in different regions.

\begin{tabular}{lcccc}
\hline \multirow{2}{*}{ Region } & \multirow{2}{*}{ WPP \# } & \multicolumn{2}{c}{ VMS Counts } & \multirow{2}{*}{ Raw Match Rate } \\
\cline { 3 - 4 } & & Match & Predicted & \\
\hline Natuna Sea & WPP 711 & 19,982 & 45,341 & $44.10 \%$ \\
\hline \multirow{2}{*}{ Makassar Strait } & WPP 712 & 31,827 & 71,456 & $44.50 \%$ \\
& WPP 713 & & & \\
ine Maluku Sea & WPP 715 & & & $0.35 \%$ \\
& WPP 716 & 100 & 28,825 & \\
\hline \multicolumn{5}{c}{ WPP 717 } \\
\multicolumn{5}{c}{ Note: data from January 2014 to August 2016. }
\end{tabular}

Figure 10 shows the relationship between average DNB radiance and match rate for each vessel and gear type. Stick-held dipnet (BA) clearly shows a fairly stable average radiance and match rate among all vessels. Squid jigging (PC), however, has a wider spread on average radiance, but the match rate is more stable in comparison.

As shown in Figure 10c, PCK clearly shows two distinct populations with different use of lighting. While one group has a comparable average radiance and match rate with $\mathrm{BA}$, the other group uses almost no lighting and resulted in lower match rate. This result corresponds to Tables 4 and 5 that the group of points with lower radiance and match rate is mostly comprised by PCK operating in the Maluku Sea. The reason that purse seiners operating in Maluku Sea fishing ground are seldom detected by VBD can be attributed to the use of FADs instead of on-board lighting to attract their catch, as reported by Natsir and Atmaja [37]. Another explanation observed in the field survey conducted by the second author shows that almost all PCK vessels located in the Java Island carried strings of metal halide bulbs above deck as shown in Figure 11, while those in the Maluku Sea region utilizes small number of submersible lights to attract their catch.

For large pelagic purse seiner with one ship (PCOB) vessels shown in Figure 10d, although some vessels had match rate higher than 0.4 , most vessels were seldom detected by VBD with overall very 
low light usage as suggested in Table 5 and Figure 12. Most PCOB were found operating in the Indian Ocean near West Sumatra and South Java, which are WPP 572 and 573 as shown in Figure 6. There is high possibility that PCOBs also frequently utilize FADs to attract their main catch, which is tuna, hence result in lower light usage. Most longline tuna (RT) vessels use very little lighting, and are seldom detected by VBD as shown in Figure 10e. Here we include hand line tuna (HLT) vessels which is one of the gear types with highest match rate instead of carrier $(\mathrm{P})$ which has raw match rate less than 1\% (see Table 3) in Figure 10f. Although the VMS database only includes a small number of HLT vessels, most were frequently detected by VBD and utilized a decent amount of lighting.
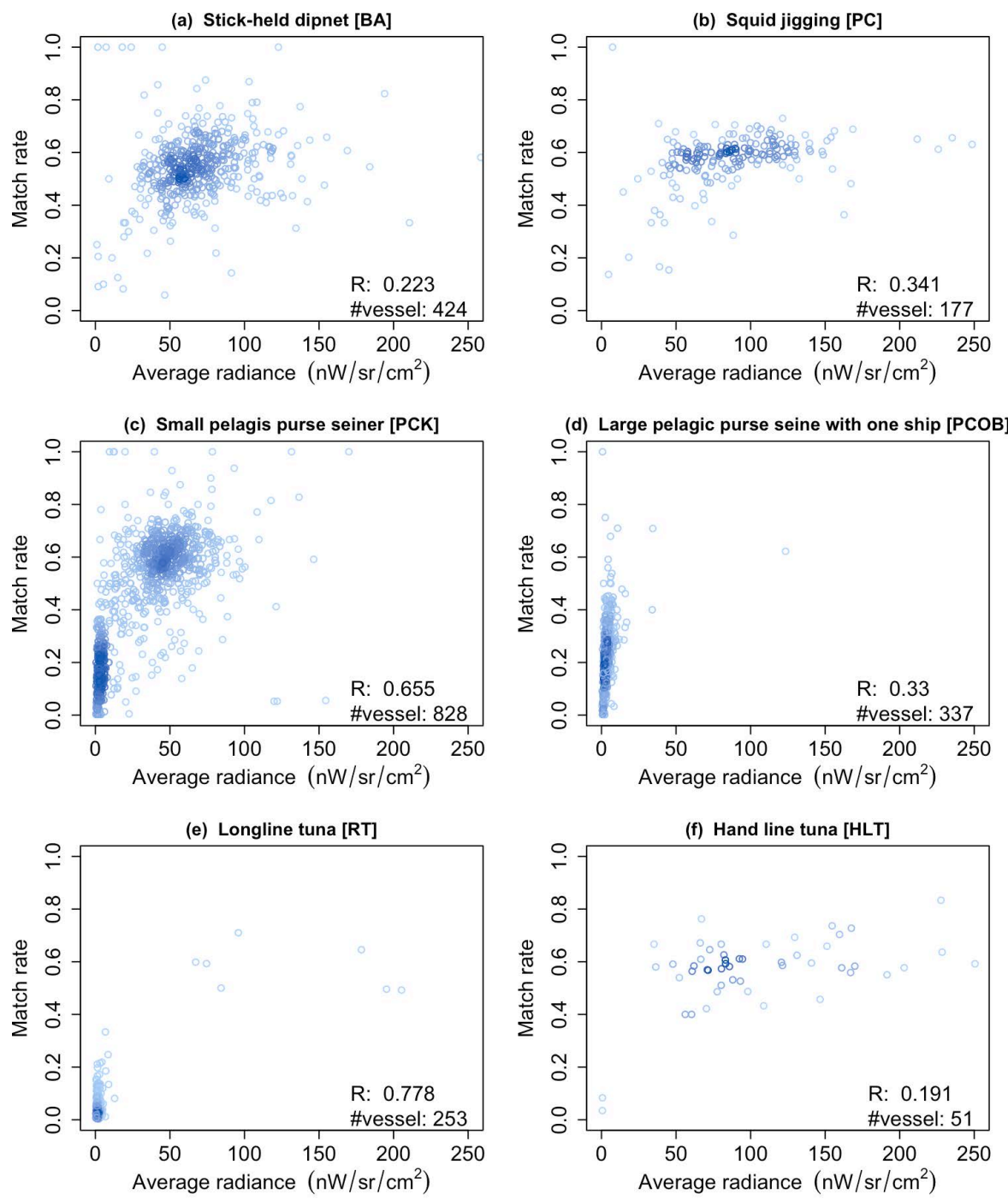

Figure 10. Scatter plot of average radiance and match rate by vessel by gear types. Carrier (P) is excluded due to too low match rate. Hand line tuna (HLT) is added instead for it having substantially high match rate. 
(a)

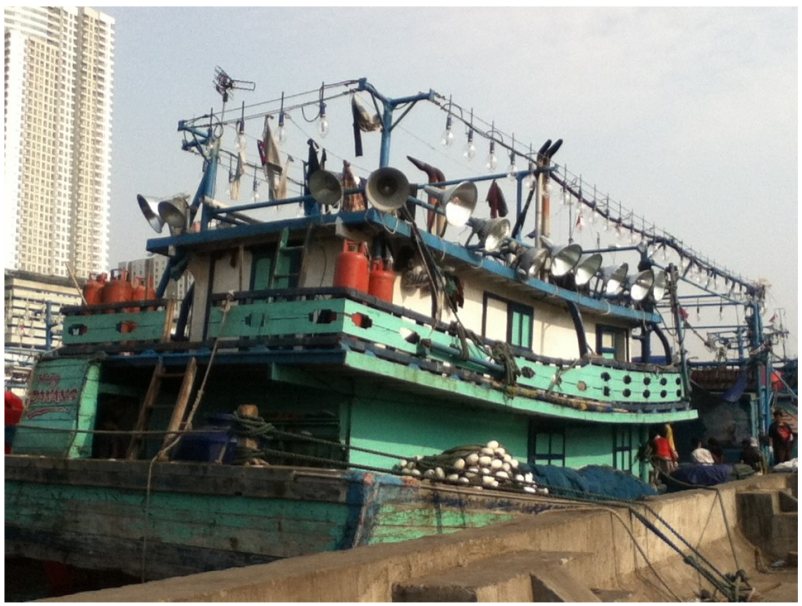

(b)

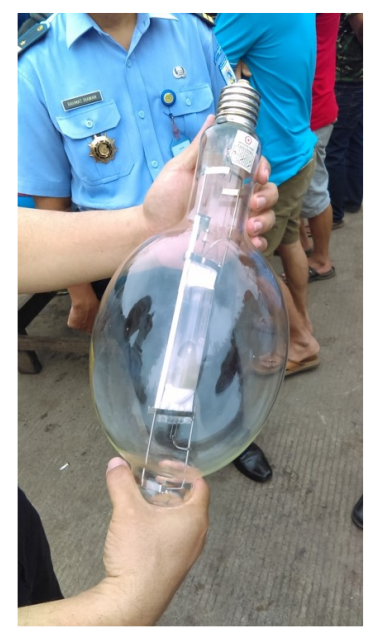

Figure 11. Photos taken during field survey in Indonesia. (a) Purse seiner at Muara Angke Port, Jakarta. Equipped with 60 bare 1500 watt metal halide bulbs, and 24 shielded bulbs pointing into the water. (b) Closeup look of a 1500 watt metal halide bulb.

As displayed in Table 5, the average radiance for all gear types are listed, with PCK further split into three regions. By viewing the overall average radiance, handline (PUR) vessels use the brightest light albeit comprised by only small number of vessels. Most gear types were relatively stable throughout the years, except RT had grown noticeable brighter. This could indicate that RT was adopting fishing with lights beginning at 2015.

Table 5. Average radiance of gear types.

\begin{tabular}{|c|c|c|c|c|c|}
\hline \multirow{2}{*}{ Gear Type } & \multirow{2}{*}{ Region } & \multicolumn{4}{|c|}{ Average Radiance $^{1}$} \\
\hline & & 2014 & 2015 & $2016^{2}$ & All \\
\hline Handline (PUR) & & - & - & 126.50 & 126.50 \\
\hline Handline tuna (HLT) & & 109.63 & 127.24 & 95.22 & 104.61 \\
\hline Squid jigging $(\mathrm{PC})$ & & 78.36 & 99.37 & 89.73 & 89.52 \\
\hline Stick-held squid dipnet (BA) & & 68.87 & 70.58 & 72.13 & 70.78 \\
\hline \multirow{4}{*}{ Small pelagic purse seiner (PCK) } & All & 39.47 & 40.48 & 45.45 & 42.23 \\
\hline & Natuna Sea & 48.46 & 46.16 & 52.85 & 48.87 \\
\hline & Makassar Strait & 43.63 & 46.64 & 40.61 & 46.50 \\
\hline & Maluku Sea & 4.48 & 3.09 & 3.48 & 4.24 \\
\hline Shark gillnet (JLB) & & 41.55 & 19.93 & 25.60 & 26.44 \\
\hline Longline tuna (RT) & & 1.74 & 26.08 & 35.61 & 24.01 \\
\hline Carrier $(\mathrm{P})$ & & 30.17 & 5.42 & 14.19 & 23.37 \\
\hline Large pelagic purse seine with one ship (PCOB) & & 4.87 & 4.19 & 4.76 & 4.58 \\
\hline Basic longline (RD) & & 3.24 & 3.30 & 4.48 & 3.43 \\
\hline Oceanic gillnet (JIO) & & 4.51 & 2.61 & 1.34 & 3.27 \\
\hline Pole and line $(\mathrm{H})$ & & 3.00 & 2.97 & 3.08 & 2.99 \\
\hline Trawler (PI) & & 2.67 & 4.17 & - & 2.72 \\
\hline Small pelagic purse seine group (PCGK) & & - & 2.48 & 1.87 & 2.32 \\
\hline Shrimp trawl (PU) & & 1.33 & 1.34 & - & 1.33 \\
\hline
\end{tabular}

${ }^{1}$ Unit: $\mathrm{nW} / \mathrm{sr} / \mathrm{cm}^{2} .{ }^{2}$ Till 2016 August. Note: regional names and numbers are in italic. 


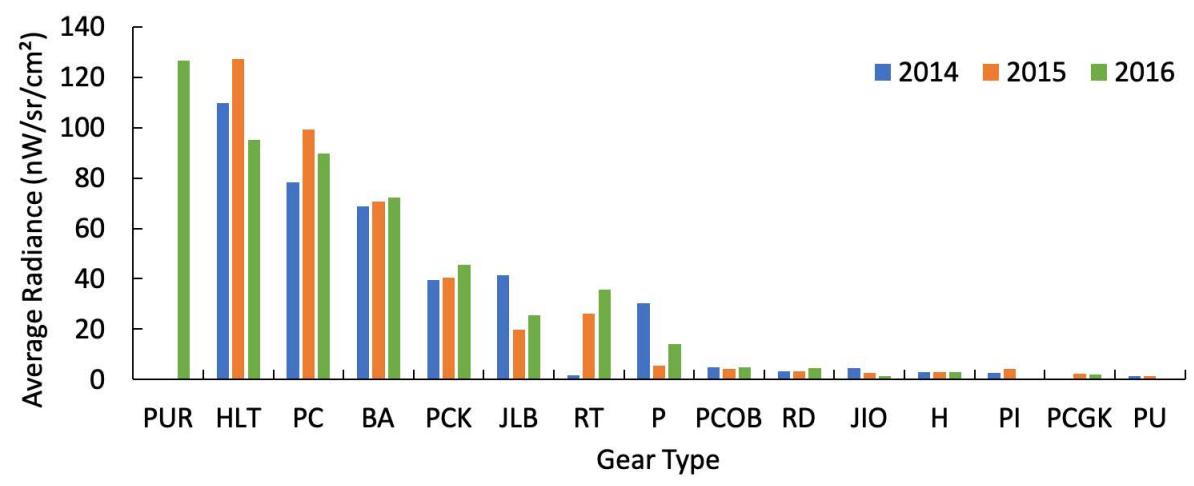

Figure 12. Average radiance of gear types.

The increasing average radiance level has a positive correlation to the match rate as shown in Figure 13. PC and BA were among those gear types with best match rate and highest radiance, due to the application of high wattage lamps to attract squid during operation. Moreover, the fishing vessel (PC and BA) only had short movement (500-700 m) within the fishing ground, making the matched VBD record substantially representative for the general location of the vessel during the day.

The handline (PUR) and handline tuna (HLT) did not commonly use lights to attract their catch. The fisherman of HLT and PUR use lights to catch squid and other fish as the main natural bait for tuna fishing. The number and wattage of lamp types on HLT and PUR fishing vessel varies. The bare metal halide bulbs of 1000 and 1500 watts were commonly used as attractant lamp. Boats were usually equipped with 10 to 20 lamps, evenly installed on both sides of the vessel [38,39]. Operations of PUR and HLT to catch bait are similar to PC with limited movement in the same fishing ground.

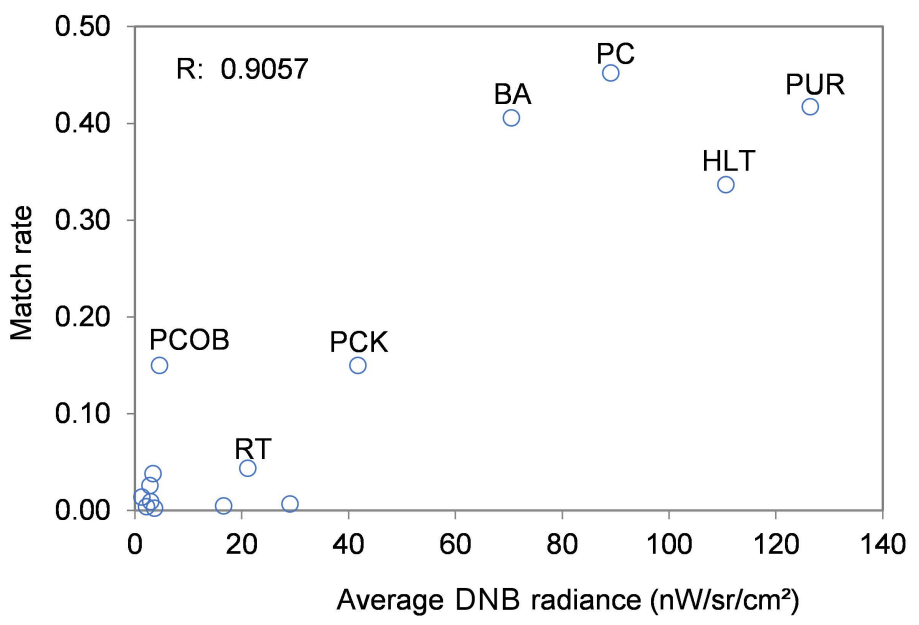

Figure 13. Relationship of average radiance and raw match rate by gear type

Figure 14 shows the map of average DNB radiance for VMS records with matched VBD record. By only taking records with best quality (VBD quality flag $=1$ ), we are confident in accounting observations without additional uncertainties. Furthermore, the map only shows cells with more than five records to ensure the map represents repetitive behaviors. It is clear that vessels within the Java Sea and the Arafura Sea were much brighter than those operating in the Indian Ocean. It is suspected the radiance difference was related to FADs usage in deeper waters in the Indian Ocean, and the differences in light requirement for PCOB operations which is more dominant in the Indian Ocean. However, the exact reason remains to be investigated. 


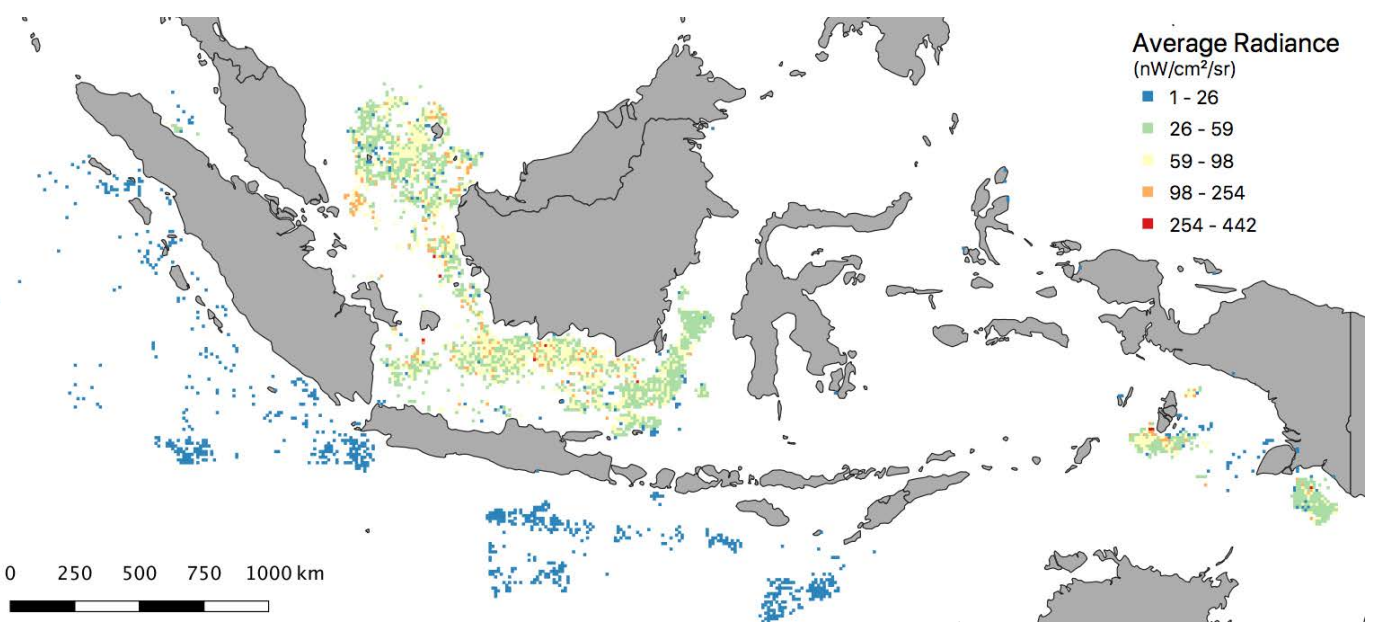

Figure 14. Map of average day night band (DNB) radiance for matched VMS records with VBD quality flag $($ QFQF_Detect) $=1$ in 0.1 degree cell (only showing cells with more than five records)

\subsection{VMS and VBD Record Uniqueness}

Table 6 shows the summary of cross-matching by comparing the matched and missed records for both VBD and VMS. The records were limited within WPP zones to ensure fair comparison. For VMS, $20 \%$ of the predicted records were matched by VBD. The missed predicted VMS records can be due to non-fishing activities, or fishing without heavy lights.

For VBD, only $6.72 \%$ of the records were matched by predicted VMS records. This implies that a huge portion of lit marine activities took place at night were not accounted by the VMS. The majority of these VBD records can be contributed by smaller vessels which are not required to carry VMS. These unique VBD records can also be an indication of "dark vessels". It is clear that the matched record number for VMS was larger than VBD. Such was caused by multiple VMS being matched to the same VBD record. This is elaborated in Section 3.6.

Table 6. Match summary for records within Indonesian WPP.

\begin{tabular}{crrrrr}
\hline & \multicolumn{2}{c}{ VBD $^{1}$} & & \multicolumn{2}{c}{ VMS $^{2}$} \\
\cline { 2 - 3 } \cline { 5 - 6 } & Count & Percent & & Count & Percent \\
\hline Match & 143,917 & $6.72 \%$ & & 158,119 & $19.99 \%$ \\
Miss & $1,996,168$ & $93.28 \%$ & & 632,988 & $80.01 \%$ \\
Sum & $2,140,086$ & $100 \%$ & & 791,107 & $100 \%$ \\
\hline
\end{tabular}

1 Accounting for data from January 2014 to August 2016 and all QF_Detect flags. ${ }^{2}$ Only count predicted records.

\subsection{Multiple Matches}

It is possible for one VBD pixel to match to more than one VMS vessel. However, this was infrequent, with $96 \%$ of the matches formed with a single VBD and single VMS boat. For the five major gear types (not including carrier (P)), only 5800 involved multiple VMS vessels out of 152,913 matches within Indonesia WPPs. In some cases the multiple matches can be due to one boat using lights to attract catch and the other VMS vessel in transit. Another possible scenario could be that there were multiple VMS vessels in close proximity to exploit a particularly rich fishing ground. Figure 15 shows the histogram of the count of VBD records ranking by the numbers of VMS matches associated for major gear types, with the highest one having $54 \mathrm{VMS}$ matches. It is clear that VMS records of stick-held squid dipnet (BA) and squid jigging (PC) vessels have the highest chance of being matched to the same VBD records.

Figure 16 shows the extreme example of 54 VMS records matching to a single VBD record. The scene was found on 22 March 2013 in the Arafura Sea about $125 \mathrm{~km}$ south-west from Merauke. 
It is a known popular squid jigging ground. Within all the matches, 40 are PC, while eight were hand line tuna (HLT) vessels, two BA, and one hand line (PUR). It is a potential example of the existence of fishing vessel sharing a smaller group or even one light vessel. This was possibly due to their tendency to fish in smaller fishing grounds with a large number of vessels, with shorter movements during fishing.

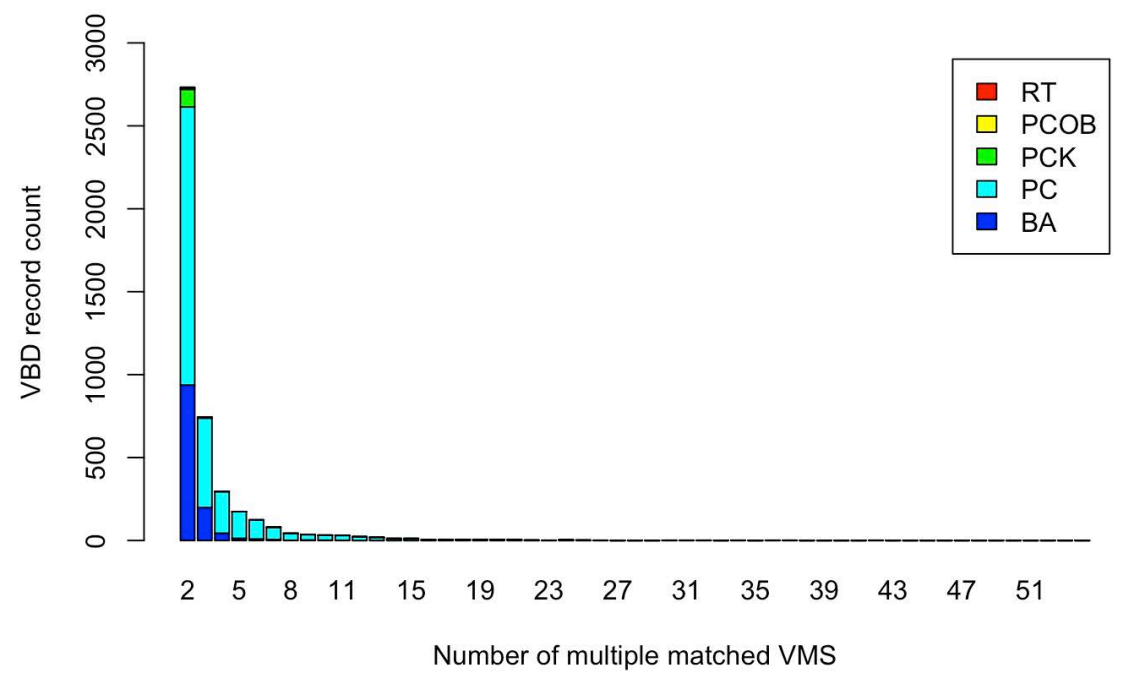

Figure 15. VBD multi-match histogram accounting only matches with fishing VMS records within Indonesia WPPs for major gear types.

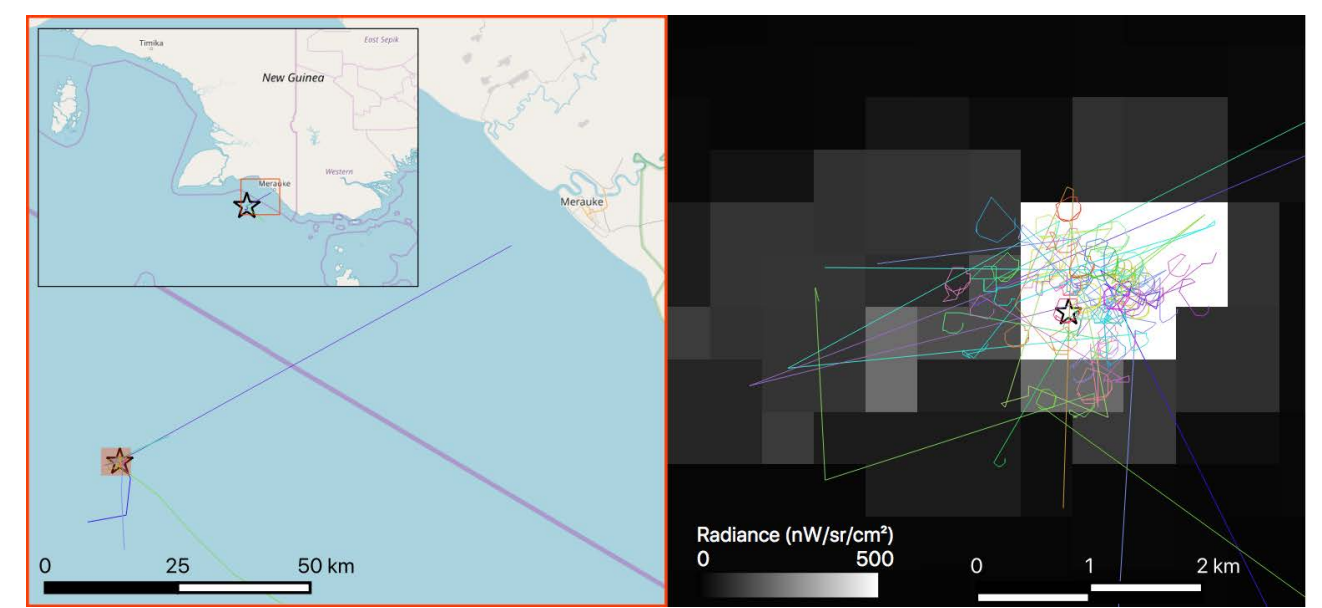

Figure 16. Map of fifty-four vessels matched to single VBD record found in the Arafura Sea, about $125 \mathrm{KM}$ south-west from Merauke. Forty of them were squid jigging (PC) vessels with the rest composed of stick-help squid dipnet (BA) and handline tuna (HLT). Track of the same UTC day was plotted with different color for each vessel. The VBD record is marked with a star. The right half of the map shows a magnified view of the tangled vessel tracks. With the DNB image as the base layer, it can be clearly seen how bright the cluster of vessels are. Basemap provided by OpenStreetMap [34]

\subsection{Matched QF_Detect}

VBD provides QF_Detect to further discriminate detection based on their quality, here in Table 7 shows a break down of QF_Detect of found VBD match over the three annual periods. In practice, VBD records with QF_Detect of 1, 2, 3, 8, and 10 were regarded as possible fishing activities. The distribution of QF_Detect for matched VBD records followed that of all VBD population as shown by quoted 
percentages in Table 7, indicates the chance of VBD to be matched by a VMS record is comparable regardless of its QF_Detect state.

Table 7. Number of matched VBD records break down by quality flag (QF_Detect).

\begin{tabular}{|c|c|c|c|c|c|c|}
\hline \multirow{2}{*}{ QF_Detect } & \multirow{2}{*}{ Explanation } & \multicolumn{4}{|c|}{ Matched VBD counts } & \multirow{2}{*}{ All VBD Counts ${ }^{1,2}$} \\
\hline & & 2014 & 2015 & $2016^{1}$ & Total & \\
\hline 1 & Boat & 35,218 & 37,141 & 46,200 & $118,559(74.9 \%)$ & $1,420,332(71.2 \%)$ \\
\hline 2 & Weak & 4098 & 5102 & 6069 & $15,269(9.6 \%)$ & $220,523(11.1 \%)$ \\
\hline 3 & Blurry & 2827 & 2732 & 2497 & $5556(3.5 \%)$ & $59,491(3.0)$ \\
\hline 8 & Recurring light & 3669 & 8214 & 4615 & $16,498(10.4 \%)$ & $218,707(11.0 \%)$ \\
\hline \multirow[t]{2}{*}{10} & Weak and blurry & 626 & 916 & 845 & $2387(1.5 \%)$ & $27,354(1.4 \%)$ \\
\hline & Sum & 46,435 & 54,105 & 60,206 & $158,269(100.0 \%)$ & $1,994,772(100.0 \%)$ \\
\hline
\end{tabular}

${ }^{1}$ Till 2016 August. ${ }^{2}$ Within Indonesia WPP. Note: see VBD web site [18] for details on quality flag (QF) definitions.

\subsection{Matched VMS Status}

Here we break down the percentage of status for predicted vessel locations having VBD matches. As shown in Figure 17, it is clear that most matches were found when the vessel is in the status of fishing or stationary. $67 \%$ of longline tuna (RT) matches were found in fishing status, while other major gear types all have more than $90 \%$. RT with substantial matches found in transit status indicate that RT vessels used a significant amount of light while being recognized as in transit. This can be due to lights being used when longliners deploy snoods with baited hooks while moving in relatively higher speed.

It is also worth noticing that small pelagic purse seiner (PCK) and stick-held squid dipnet (BA) were often bright when in the status of stationary than maneuvering, unlike other major gear type spending more lit time in maneuvering. This could also be attributed to how and what vessels of those gear types are fishing.

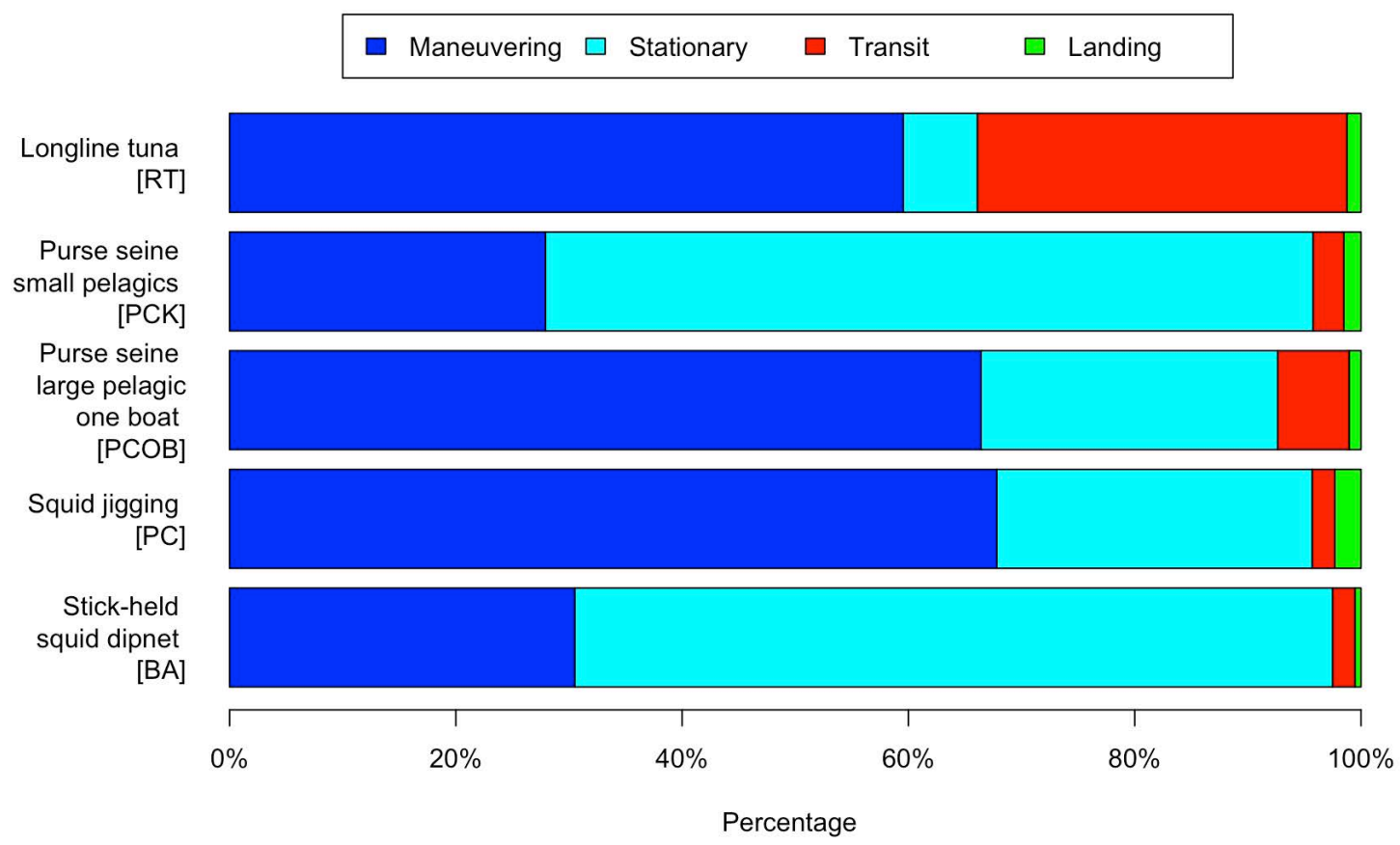

Figure 17. Proportion of status for matched VMS records for major gear types. 


\section{Discussion}

Our study has four objectives: (1) to identify the gear types that are commonly detected by VIIRS in Indonesia, (2) to rate the probability that a boat is fishing if it is detected by VIIRS, (3) to determine the probable gear type for a VBD in Indonesia fishery management zones (WPP), and (4) to determine if different styles of lighting can be discerned. To address these objectives we combined two types of data. The reference data are 32 months of VMS data supplied by the Indonesia Ministry of Marine Affairs and Fisheries (MMAF). The subject data are VIIRS boat detections from the same 32 months. Out of 3683 VMS equipped vessels, 2632 had at least one VBD match.

The methodology can be divided into two parts. The first is an algorithm for cross-matching VIIRS boat detections with VMS tracks. The process involves predicting the probable location of a VMS equipped vessel at the time of each VIIRS data collection using an orbital model. The probable vessel location is interpolated between the two immediate neighboring VMS records found before and after the predicted VIIRS overpass time. Matches are confirmed if the VIIRS has a vessel detection within $700 \mathrm{~m}$ and $5 \mathrm{~s}$ of the predicted location. The second part involves algorithm to segments and classifies VMS records into landing, transit and fishing activity types based on their location, velocity and change in heading.

VMS/VBD match rates were calculated separately for the transit and fishing activity types. The gear types show two different types in VBD match rates for the fishing activity type. Our interpretation is that gear type with low match rates are not using lights to attract catch and are only occasionally detected when nighttime operations call for extra deck lighting. This is the group with fishing match rates less than $11 \%$ : basic longline $(\mathrm{RD})$, longline tuna $(\mathrm{RT})$, pole and line $(\mathrm{H})$, carrier $(\mathrm{P})$, gill net (JIO/JLB), and trawlers (PI/PUD). Gear types that are routinely using lighting to attract catch, with match rates in excess of $30 \%$ include two types of squid boats (jigging and stick dipnet), handline, handline tuna, and two types of purse seiners. The match rates for transit activity lacks this two-typed distribution and is consistently in the $0-10 \%$ range, comparable to the range found for gear types that are not using lights to attract catch. Based on these results we conclude that if a vessel is detected by VIIRS, there is a $96.42 \%$ probability that it is fishing.

The difference in light usage during fishing may also associate with the use of fish aggregating devices (FADs). FADs are known to be a common practice, enabling fishermen to use minimal effort for maximal catch. FADs are extensively used to attract tuna, for they tend to be attracted by floating objects. The exact number and distribution of FADs is unclear, while licensed numbers in Indonesia in 2006-2008 counts near 100 [36], some say there are 3858 or more FADs existed in Indonesian water [40]. Deployment of deep-sea FADs are reported to be found in provinces like North/West Sumatra, Lampung, east/west Java, Celebes, Maluku and Papua [36], which has immediate access to deep waters as shown in Figure 1. In these waters, we found smaller numbers of VBD/VMS matches as shown in Figure 7, and with very little to no vessel lighting observed as shown in Figure 14. This connection implies that the two-typed distribution on match rate for purse seiners operating in Indonesia is due to the difference in how they operate. Those operating in WPP 715, 716, and 717 are utilizing deep-water FADs while those in WPP 712 and 713 are not. Likewise, large pelagic purse seine with one ship (PCOB) operating in WPP 572 and 573 also more likely to rely on deep-water FADs hence they used less lighting compared to those operating in shallow waters. Overall, as Figure 14 suggests, all bright lighting is observed in shallow waters including WPP 711, 712, and 718, while deep water regions like WPP 572, 273, 714, 715, 716, and 717 seldom detects bright lights.

During the 32 month data period, there were 2.1 million VBD records and the match rate to VMS vessels was $6.72 \%$. Thus $93 \%$ of the VBD ( 2 million) records were not represented in the VMS record. We believe the vast majority of the VBD lacking VMS are from vessels using lights to attract catch that are under 30 GT level that triggers the VMS requirement. Other possible reasons why vessels may be detected by VIIRS but lack VMS are the possibilities that the vessel has turned off their VMS or is an illegal foreign fishing vessel. The spatial context of the VBD lacking VMS may be used to guide the 
interpretation. For instance, VBD lacking VMS in the far northern part of the Natuna Sea are suspect as foreign fishing vessels.

By taking the gear type match rates as a sample representing the gear types engaged in fishing with lights it is possible to calculate the probable gear types for VBD (Table 8). Across all of Indonesia it is most likely to find a VBD representing a small pelagic purse seiner (PCK). This is the most likely gear type for VBD in 6 of the eleven WPP zones $(571,572,711,713,715$, and 716). For the remaining five WPP the probable gear type for a VBD ranges from large pelagic purse seine with one ship (PCOB) in WPP 573, squid dipnet (BA) in WPP 712, longline tuna (RT) in WPP 717 and 714, and squid jigging in WPP 718.

Table 8. Dominant gear type with matched VMS/VBD in each WPP.

\begin{tabular}{lllc}
\hline WPP \# & Region & Dominant Gear Type & Percentage \\
\hline WPP 571 & Malacca Strait & Small pelagic purse seiner (PCK) & $97.20 \%$ \\
WPP 572 & West of Sumatra & Small pelagic purse seiner (PCK) & $48.17 \%$ \\
WPP 573 & South of Java & Large pelagic purse seine with one ship (PCOB) & $78.83 \%$ \\
WPP 711 & Natuna Sea & Small pelagic purse seiner (PCK) & $62.64 \%$ \\
WPP 712 & Java Sea & Stick-held squid dipnet (BA) & $63.47 \%$ \\
WPP 713 & Makassar Strait & Small pelagic purse seiner (PCK) & $98.80 \%$ \\
WPP 714 & Banda Sea & Longline tuna (RT) & $24.43 \%$ \\
WPP 715 & Maluku Sea & Small pelagic purse seiner (PCK) & $60.32 \%$ \\
WPP 716 & Sulawesi Sea & Small pelagic purse seiner (PCK) & $87.14 \%$ \\
WPP 717 & North Papua & Longline tuna (RT) & $50.00 \%$ \\
WPP 718 & Arafura Sea & Squid jigging (PC) & $75.47 \%$ \\
\hline
\end{tabular}

Note: Carrier $(\mathrm{P})$ is not included in this table due to being not a fishing vessel and has been banned from further operations.

Consideration of the match rates versus average radiance indicates that most gear types have a largely consistent style of lighting. The exception is small pelagic purse seiner (PCK), which shows two distinct populations of vessel lighting styles in Figure 10c. There is one loose cluster with a center of mass near $60 \%$ raw match rate and an average radiance of $50 \mathrm{nW} / \mathrm{sr} / \mathrm{cm}^{2}$. The other population forms a largely vertical column in Figure 10c, with raw match rates less than $40 \%$ and average radiances less than $5 \mathrm{nW} / \mathrm{sr} / \mathrm{cm}^{2}$. Tables 4 and 5 offers a geographical clue in that PCK has high match rates with brighter lighting in the Natuna Sea and Makassar Straits and extremely low match rates in the Maluku Sea with dimmer lighting. In tracing the geography of the vertical column cluster of Figure 10c we found these vessels are operating in the Maluku Sea. The second author conducted lighting surveys on PCK vessels at landing sites on Java Island and in the Maluku Sea region (Ambon and Bitung). The PCK at Java landing sites invariably carried string of bare metal halide bulbs above the deck edges, in some cases reaching 100,000 watts in total.

Besides the using of FADs, in Ambon and Bitung the PCK still use lights to attract catch, but deploy small numbers of submersible lights. Field survey of lighting used on PCK vessels operating out of Ambon and Bitung indicates the boats have 1000 to 3000 watts of deck lighting and use 1000 to 8000 watts of submersible lighting as shown in Figure 11. Our interpretation is the vertical column on Figure 10c is an indication for the use of submersible lighting. Certainly the detection of submersible lighting on fishing boats by satellite is quite challenging. Not only is the wattage used quite small but also the water is opaque in the near infrared, which covers half of the DNB bandpass, which straddles the visible and NIR. This study lays the foundation for further study to improve VBD regarding this issue.

While no field data has been collected on PCOB, it is clear from Figure 10d that he primary cluster is a vertical column quite similar to the one seen on Figure 10c. This suggests that PCOB vessels are commonly using submersible lights. Another gear type with a similar vertical column cluster is longline tuna (RT). Submersible LED lights are widely used to attract catch on RT vessels [41], with on board lighting also becoming more popular in recent years as shown in Table 5. Based on 
these new understandings, we can further investigate the impact on VBD resulted from difference lighting methods.

\section{Conclusions}

A methodology has been developed for cross-matching VIIRS boat detections with status-classified VMS tracks. The process involves predicting the probable location of a VMS equipped vessel at the time of each VIIRS data collection. An orbital model is used to calculate VIIRS overpass times. VMS tracks are segmented and classified by their location, speed, and heading change to determine the status of each record. The algorithm can also be applied to AIS tracks.

Given an extended temporal record, it would be possible to develop DNB lighting profiles for individual VMS vessels, providing additional information for more detailed analyses of vessel behavior. Such vessel specific profiles could include the overall match rate, spatial distribution of matches, and radiance levels. It is also possible to derive group profiles for all vessels of a specific gear type or associated with a specific landing site.

There are several applications for cross-matching VIIRS boat detections with GPS based vessel tracks. If the matching is done in near real time as VBD and VMS data becomes available, it will be a great help to the authororties by identifying "dark vessels" that lack an operating VMS or AIS system. In some areas, this is a tip-off for potentially illegal fishing. Examples may include fishery closures, restricted waters, or Exclusive Economic Zone (EEZ) boundary zones. It is reasonable to assume that most AIS and VMS vessels operate legally most of the time. It has been reported that vessels turn off their AIS or VMS devices while engaged in illegal fishing. Thus a VBD lacking AIS or VMS in fishing grounds where all vessels should reasonably have one or the other is instantly suspect in terms of IUU fishing. Another potential application is the identification of offshore transshipment events. Several organizations analyze AIS and VMS tracks to identify transshipment events [42-44]. The typical positive identification of transshipment is two or more stationary vessels in an offshore location. The conclusion is particularly strong if one of the vessels is registered as a carrier or transporter. But what about the cases where an AIS or VMS vessel is "loitering" with no other AIS or VMS vessel present? If the loitering period extends after midnight, our methods make it possible to check for VBD matches that may indicate a transshipment event. This evidence could be interpreted relative to the DNB match rate and radiance profile of the subject AIS or VMS vessel. Common questions from the VBD users are what type of vessels are detected by VIIRS and can the VBD be interpreted as fishing activity, as opposed to transit? The results from this study confirmed that in Indonesia, five gear types including squid fishing, lift net, and purse seiners commonly deploy and operate lights to attract catch. This includes what are the detection limits in terms of light output. The results from this study show that given an extended period of observation, it is possible to develop match rate profiles for individual vessels that can be used with some advantage.

The vast numbers of VBD that lack VMS testify to the value of the VBD data in monitoring fishing grounds where lighting is used to attract catch. In fishing grounds where lights are used to attract catch, VBD provide the most complete near real time data source for locating fishing activity. EOG posts the latest VBD output within 4 to $6 \mathrm{~h}$ from satellite overpass. The time includes data gathering and processing.

Further development of this study can be used to estimate unreported catch and improve stock assessments as well as other related information relevant for decision makers. Moreover, improved monitoring programs can benefit the assessment of efficient harvest strategies through improved estimates of maximum sustainable yield (MSY), biomass and carrying capacity of the fishery [45]; while the problems with catch under-reporting appear to be particularly serious in Indonesia, especially for catches of tuna and tuna like species [46].

Verifying the reported logbooks against landing data using VBD and VMS data proposed by this research, could address the problem of uncertainty in the level of reporting from fishers to the fishing port authority. The urgency of such verification using VBD and VMS data is due to the current trip 
length which was estimated by the number of fishing days by departure and arrival dates of vessels, while some purse-seine vessels, however, transfer their catch to a carrier vessel that brings the catch ashore without any proper catch reporting to the authority.

Author Contributions: F.C.H. developed the cross matching and VMS track segmentation software, processed the VMS records, and was the primary writer of the paper. C.E. wrote the introduction, discussion and conclusion. M.Z. wrote the VBD algorithms. K.B. processed the VIIRS data to generate the VBD. T.G. assisted K.B. in generating the VBD data. D.K. provided technical details on the VMS data. A.S.,W.B., and M.R. reviewed the manuscript and provided local knowledge. R.N. and Y.S. helped provide local knowledge and VMS data.

Acknowledgments: This research was funded in part by the NOAA JPSS proving ground program and the U.S. Agency for International Development. The research was possible thanks to the collection of VMS data by the Indonesia Ministry of Marine Affairs and Fisheries. Our access to the VMS records was arranged for use in research through Global Fishing Watch. The paper benefited from a detailed review provided by John Mittleman, Naval Research Laboratory, Washington, DC.

Conflicts of Interest: The authors declare no conflict of interest.

\section{Abbreviations}

The following abbreviations are used in this manuscript:

$\begin{array}{ll}\text { AIS } & \text { Automatic identification system } \\ \text { DMSP-OLS } & \text { Defense Meteorological Satellite Program-Operational Linescan System } \\ \text { DNB } & \text { Day night band } \\ \text { FAD } & \text { Fishg aggregating device } \\ \text { GFW } & \text { Global Fishing Watch } \\ \text { GT } & \text { Gross tonnage } \\ \text { EEZ } & \text { Exclusive Economic Zone } \\ \text { EOG } & \text { Earth Observation Group } \\ \text { IMO } & \text { International Maritime Organization } \\ \text { IUU } & \text { Illegal, Unreported and Unregulated } \\ \text { MMAF } & \text { Ministry of Maritime Affairs and Fisheries } \\ \text { MSY } & \text { Maximum sustainable yield } \\ \text { NASA } & \text { National Aeronautics and Space Administration } \\ \text { NOAA } & \text { National Oceanic and Atmospheric Administration } \\ \text { SAR } & \text { Synthetic aperture radar } \\ \text { Suomi NPP } & \text { Suomi National Polor-orbiting Partnership } \\ \text { TLE } & \text { Two line element } \\ \text { UTM } & \text { Universal transverse mercator } \\ \text { VBD } & \text { VIIRS boat detection } \\ \text { VIIRS } & \text { Visual infrared imaging radiometer suite } \\ \text { VMS } & \text { Vessel monitoring system } \\ \text { WPP } & \text { Wilayah Pengelolaan Perikanan (Fishery Management Area) } \\ & \end{array}$

\section{References}

1. Suhendar, M. Comparison of Vessel Monitoring System (VMS) between Iceland and Indonesia [Final Project]. Available online: http:/ / www.unuftp.is/static/fellows/document/suhendar12prf.pdf (accessed on 15 August 2018).

2. Enforcement I NOAA Fisheries. Available online: https://www.fisheries.noaa.gov/topic/enforcement\# vessel-monitoring (accessed on 21 August 2018).

3. Automatic Identification System (AIS). Available online: http://www.imo.org/en/OurWork/safety/ navigation/pages/ais.aspx (accessed on 10 August 2018).

4. Tello, M.; Lopez-Martinez, C.; Mallorqui, J.J. A novel algorithm for ship detection in SAR imagery based on the wavelet transform. IEEE Geosci. Remote Sens. Lett. 2005, 2, 201-205. [CrossRef]

5. Greidanus, H.; Clayton P.; Indregard M.; Staples G.; Suzuki N.; Vachoir P.; Wackerman C.; Tennvassas T.; Mallorqui J.; Kourti N.; et al. Benchmarking operational SAR ship detection. In Proceedings of the IEEE International Geoscience and Remote Sensing Symposium, Anchorage, AK, USA, 20-24 September 2004. 
6. Wu, G.; de Leeuw, J.; Skidmore, A.K.; Liu, Y.; Prins, H.H.T. Performance of LandsatTM in ship detection in turbid waters. Int. J. Appl. Earth Obs. Geoinf. 2009, 11, 54-61. [CrossRef]

7. Máttyus, G. Near real-time automatic marine vessel detection on optical satellite images. In Proceedings of the International Archives of the Photogrammetry, Remote Sensing and Spatial Information Sciences, ISPRS Hannover Workshop, Hannover, Germany, 21-24 May 2013.

8. Corbane, C.; Najman, L.; Pecoul, E.; Demagistri, L.; Petit, M. A complete processing chain for ship detection using optical satellite imagery. Int. J. Remote Sens. 2010, 31, 5837-5854. [CrossRef]

9. Zhu, C.; Zhou, H.; Wang, R.; Guo, J. A novel hierarchical method of ship detection from spaceborne optical image based on shape and texture features. IEEE Trans. Geosci. Remote Sens. 2010, 48, 3446-3456. [CrossRef]

10. Croft, T.A. Night-time images of the earth from space. Sci. Am. 1978, 239, 68-79. [CrossRef]

11. Elvidge, C.D.; Baugh, K.; Zhizhin, M.; Hsu, F.-C. Why VIIRS data are superior to DMSP for mapping nighttime lights. Proc. Asia-Pac. Adv. Netw. 2012, 35, 62-69. [CrossRef]

12. Oozeki, Y.; Inagake, D.; Saito, T.; Okazaki, M.; Fusejima, I.; Hotai, M.; Watanabe, T.; Sugisaki, H.; Miyahara, M. Reliable estimation of IUU fishing catch amounts in the northwestern Pacific adjacent to the Japanese EEZ: Potential for usage of satellite remote sensing images. Mar. Policy 2018, 88, 64-74. [CrossRef]

13. Guo, G.; Fan, W.; Xue, J.; Zhang, S.; Zhang, H.; Tang, F.; Cheng, T. Identification for operating pelagic light-fishing vessels based on NPP/VIIRS low light imaging data. Trans. Chin. Soc. Agric. Eng. 2017, 33, 245-251.

14. Cozzolino, E.; Lasta, C.A. Use of VIIRS DNB satellite images to detect jigger ships involved in the Illex argentinus fishery. Remote Sens. Appl. Soc. Environ. 2016, 4, 167-178. [CrossRef]

15. Liu, Y.; Saitoh, S.I.; Hirawake, T. Detection of squid and pacific saury fishing vessels around Japan using VIIRS Day/Night Band image. Proc. Asia-Pac. Adv. Netw. 2015, 39, 28-39. [CrossRef]

16. Elvidge, C.; Zhizhin, M.; Baugh, K.; Hsu, F-C. Automatic Boat Identification System for VIIRS Low Light Imaging Data. Remote Sens. 2015, 7, 3020-3036. [CrossRef]

17. Joint Polar Satellite System. Available online: http://www.jpss.noaa.gov/launch.html (accessed on 21 August 2018).

18. EOG VIIRS Boat Detection. Available online: https:/ / eogdata.mines.edu/vbd/ (accessed on 4 February 2019).

19. Guerriero, M.; Wilett, P.; Coraluppi, S.; Carthel, C. Radar/AIS data fusion and SAR tasking for Maritime Surveillance. In Proceedings of the International Conference on Information Fusion, Cologne, Germany, 30 June-3 July 2008.

20. Grasso, R.; Mirra, S.; Baldacci, A.; Horstmann, J.; Coffin, M.; Jarvis, M. Performance Assessment of a Mathematical Morphology Ship Detection Algorithm for SAR Images through Comparison with AIS Data. In Proceedings of the International Conference on Intelligent Systems Design and Applications, Pisa, Italy, 30 November-2 December 2009.

21. Margarit, G.; Tabasco, A. Ship Classification in Single-Pol SAR Images Based on Fuzzy Logic. IEEE Trans. Geosci. Remote Sens. 2011, 49, 3129-3138. [CrossRef]

22. Chaturvedi, S.K.; Yang, C.-S.; Ouchi, K.; Shanmugam P. Ship Recognition by Integration of SAR and AIS. J. Navig. 2012, 65, 323-337. [CrossRef]

23. Lemoine, G.; Ghesworth, J.; Schwartz-Juste, G.; Kourti, N.; Shepherd, I. Near real time vessel detection using spaceborne SAR imagery in support of fisheries monitoring and control operations. In Proceedings of the IEEE International Geoscience and Remote Sensing Symposium, Anchorage, AK, USA, 20-24 Septemer 2004.

24. KKP WPP MapServer. Available online: http://www.ppk-kp3k.kkp.go.id/ArcGIS/rest/services/kkp/ Kawasan/MapServer (accessed on 26 March 2019).

25. Elvidge, C.; Zhizhin, M.; Baugh, K.; Hsu, F.C.; Ghosh, T. Methods for global survey of natural gas flaring from visible infrared imaging radiometer suite data. Energies 2016, 9, 14. [CrossRef]

26. Vallado, D.A.; Crawford, P.; Hujsak, R.; Kelso, T.S. Revisiting Spacetrack Report \#3. In Proceedings of the AIAA/AAS Astrodynamics Specialist Conference, Keystone, CO, USA, 21-24 August 2006.

27. Kelso, T.S. Frequently Asked Questions: Two-Line Element Set Format. Satellite Times 1997, 4, 68-69.

28. CelesTrak. Available online: http:/ / celestrak.com/ (accessed on 5 April 2015).

29. McCluskey, S.M.; Lewison, R.L. Quantifying fishing effort: A synthesis of current methods and their applications. Fish Fish. 2008, 9, 188-200. [CrossRef]

30. De Souza, E.N.; Boerder, K.; Matwin, S.; Worm, B. Improving Fishing Pattern Detection from Satellite AIS Using Data Mining and Machine Learning. PLoS ONE 2016, 11, e0158248. 
31. Calenge, C. Analysis of Animal Movements in R: The AdehabitatLT Package. Available online: https://cran. r-project.org/web/packages/adehabitatLT/vignettes/adehabitatLT.pdf (accessed on 31 August 2018).

32. NASA Ocean Color. Available online: https://oceancolor.gsfc.nasa.gov/docs/distfromcoast/ (accessed on 17 June 2017).

33. Pusat Informasi Pelabuhan Perikanan. Available online: http://pipp.djpt.kkp.go.id (accessed on 15 August 2017).

34. OpenStreetMap. Available online: https://www.openstreetmap.org/ (accessed on 15 May 2018).

35. Baker, N.; Kilcoyne H. Joint Polar Satellite System (JPSS) VIIRS Radiometric Calibration Algorithm Theoritical Basis Document (ATBD); Rev. C; Goddard Space Flight Center: Greenbelt, MD, USA, 2013.

36. Yasfiandayani, R.; Baskoro, M.; Monintja, D. Imapct of fish aggregating device on sustainable capture fisheries. In Proceedings of the 1st International Symposium on Aquatic Product Processing 2013, Bogor, Indonesia, 13-14 November 2013. [CrossRef]

37. Natsir, M.; Atmaja, S.B. Fishing activity of individual purse seiners in Molucca Sea: Vessel Monitoring System (VMS) and observers. J. Penelitian Perikanan Indonesia 2013, 19, 17-24.

38. Mulyadi, R.A.; Brown, A.; Rengi, P. Study Technology Hand Line In Ocean Fishing Port Bungus Province West Sumatra. J. Online Mahasiswa Fakultas Perikanan Ilmu Kelautan Univ. Riau 2015, 2, 1-13.

39. Mulyadi, R.A.; Sondita, M.F.A.; Yusfiandayani, R. Suhu permukaan laut dan kedalaman tertangkapnya tuna oleh kapal pancing ulur yang dilengkapi lampu. J. Teknol. Perikanan Kelautan 2018, 8, 199-207. [CrossRef]

40. Fish Magnet Boom Creates Headaches in Indonesia'S War on Overfishing. Available online: https:// news.mongabay.com/2017/02/fish-magnet-boom-creates-headaches-in-indonesias-war-on-overfishing/ (accessed on 24 February 2019)

41. Submersible Underwater Green Fishing Lights Longline Tuna Lamp For Deep Sea. Available online: http://underwaterledfishinglights.sell.everychina.com/p-106898950-submersible-underwatergreen-\%20 fishing-lights-longline-tuna-lamp-for-deep-sea.html (accessed on 12 September 2018).

42. Miller, N.A.; Roan, A.; Hochberg, T.; Amos, J.; Kroodsma D. A. Identifying Global Patterns of Transshipment Behavior, Front. Mar. Sci. 2018, 5, 240.

43. Boerder, K.; Miller, N.A.; Worm, B.; Global hot sopts of transshipment of fish catch at sea. Sci. Adv. 2018, 4, 7159. [CrossRef]

44. European Fisheries Control Agency. Core Curriculum for the Training of Fisheries Inspectors: $2 b$ Transhipment Inspection; Europena Union: Luxembourg, 2017; ISBN 978-92-9209-944-9

45. Rudd, M.B.; Branch, T.A. Does unreported catch lead to overfishing? Fish Fish. 2017, 18, 313-323. [CrossRef]

46. Yuniarta, S.; van Zwieten, P.A.; Groeneveld, R.A.; Wisudo, S.H.; van Ierland, E.C. Uncertainty in catch and effort data of small- and medium-scale tuna fisheries in Indonesia: Sources, operational causes and magnitude. Fish. Res. 2017, 193, 173-193. [CrossRef] 